\title{
DESIGN OF A THERMOPHORETIC SAMPLING SYSTEM TO COLLECT SOOT FROM FLAMES
}

\author{
by \\ Paul Ravi Teja Chinnam \\ Bachelor of Technology, Amity University (2014), Noida, India
}

A project

presented to Ryerson University

in partial fulfilment of the

requirements for the degree of

Master of Engineering

in the program of

Aerospace Engineering

Toronto, Ontario, Canada, 2020

CPaul Ravi Teja Chinnam 2020 


\section{AUTHOR'S DECLARATION FOR ELECTRONIC SUBMISSION OF A PROJECT}

I hereby declare that I am the sole author of this project. This is a true copy of the project, including any required final revisions, as accepted by my examiners.

I authorize Ryerson University to lend this project to other institutions or individuals for the purpose of scholarly research.

I further authorize Ryerson University to reproduce this project by photocopying or by other means, in total or in part, at the request of other institutions or individuals for the purpose of scholarly research.

I understand that my project may be made electronically available to the public. 


\title{
DESIGN OF A THERMOPHORETIC SAMPLING SYSTEM TO COLLECT SOOT FROM FLAMES
}

Master of Engineering, Aerospace Engineering, Ryerson University, Toronto (2020)

\begin{abstract}
Project Objective

Design a thermophoretic sampling system and purchase all required material and equipment for the design.
\end{abstract}

\section{Methodology to be Adopted}

Study the systems available in the market and design the most effective and cost-efficient system. It includes studying different motors and associated components that are available in the market and selecting the right components to suit the purpose.

\section{Brief Summary of the Project}

The report discusses the planning phase of the project to the end of the design phase along with a few suggestions for a further scope of work. This project includes choosing the best system to design with-in the few well-known existing models such as the multi-probe system, pneumatic and electric linear motor system, amongst others. After considering multiple factors, an electric linear motor configuration architect was chosen for the design. The secondary research is to find the right motor (stator), slider, servo drive, trailing chain cable, power supply, lubricant, USB interface converter, tweezer, set screw, washer, thin hex nut, gasket sealant and a novel designed tweezer holder according to the design requirement and fabrication ease. The major objective of the design is to achieve an ultra-high-speed stroke with a residue time as little as $3 \mathrm{~ms}$ to $100 \mathrm{~ms}$ for collecting soot from different flames. Another novel highlight of the project was the TEM mesh (micro-grid) holder using a tweezer and an in-house designed tweezer holder. All the required purchase orders are placed for the components needed for designed thermophoretic sampling device. 


\section{ACKNOWLEDGEMENTS}

Numerous hours were put in to completing this project. However, it would not have been possible without the kind support and help from my project supervisor and committee members of the organization. I would like to extend my sincere thanks to all of them.

I am highly indebted to Dr. Ahmet Emre Karatas for offering the project opportunity. His guidance and constant supervision have helped me excel in this project. In addition, I will always remain grateful for his immense help and support provided in the completion of the project.

I would like to express my special gratitude and thanks to Dr.Jeffory Yokota for giving valuable advice when I initially started the master's program and also for being the chair of the committee reviewing my MEng Project.

I would also like to thank Dr. Kazem Fayazbakhsh for taking the time, and for being part of the examining committee for my project.

I would also express my gratitude and thanks to Dr. Hekmat Alighanbari for offering me a GA position in the propulsions course which led to securing this project.

I wold also express my special thanks to Sujana Alahari for timely help with proof reading and editing of the report.

Lastly, special thanks to Mr. Robert Farraway, Branch Manager of Westburne Central for his constant support over the three months in the process of product purchase and Mr. Joe Resendes, Motion Application Specialist of Westburne Ontario for his time, and for helping us to understand the technicality of components and clarifying the concerns that were raised. 


\section{TABLE OF CONTENTS}

AUTHOR'S DECLARATION FOR ELECTRONIC SUBMISSION OF A PROJECT ...............ii

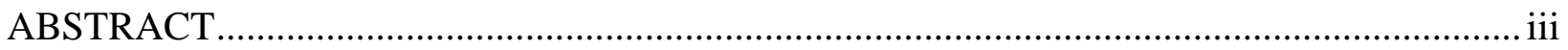

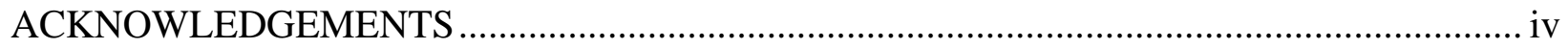

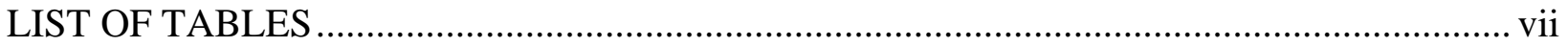

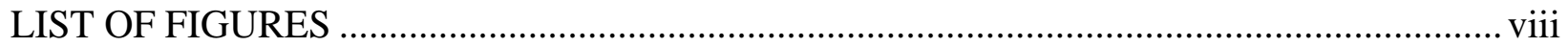

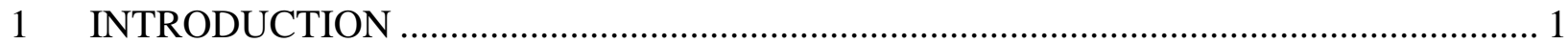

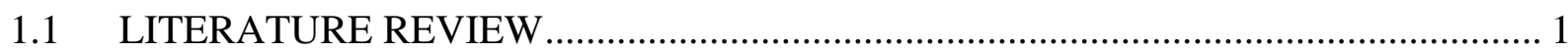

1.1.1 PNEUMATIC SYSTEM ARCHITECT ….................................................... 1

1.1.2 MULTI-PROBE SYSTEM ......................................................................... 2

1.1.3 LINEAR MOTOR SYSTEM ........................................................................... 3

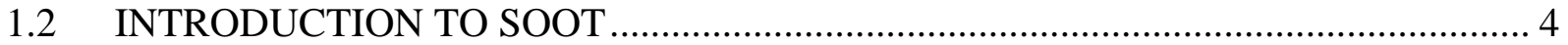

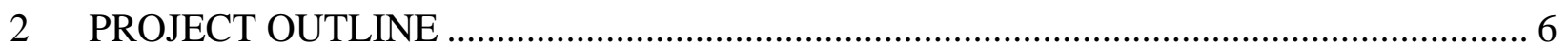

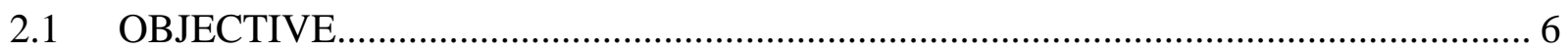

2.2 TIMELINE OF THE PROJECT FROM AUGUST 2019 TO JANUARY 2020............ 6

2.3 LIST OF ITEMS PURCHASED/SELECTED FOR THE PROJECT …...................... 7

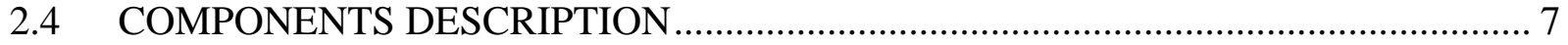

2.4.1 LINEAR MOTOR (STATOR) …............................................................ 7

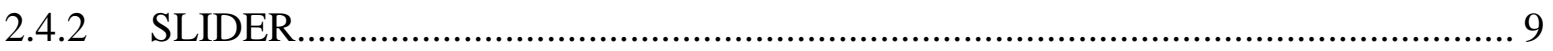

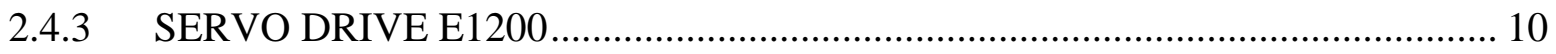

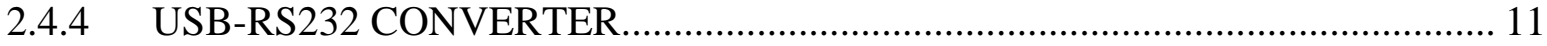

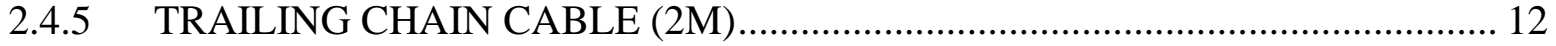

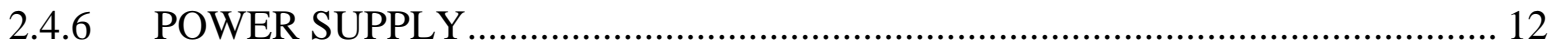

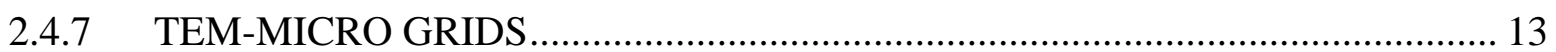

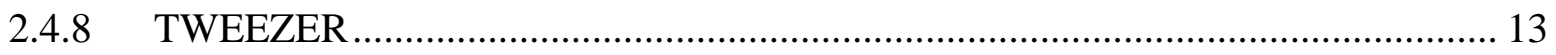

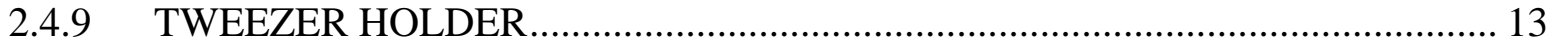

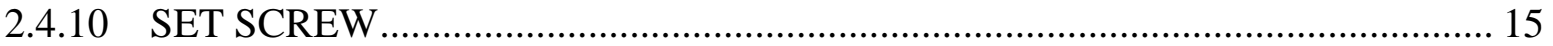

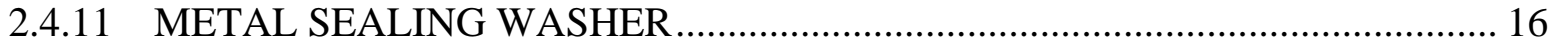

2.4.12 THIN HEX NUT..................................................................................... 17

2.4.13 GASKET MAKER SEALANT ................................................................ 17

2.4.14 LUBRICANT OF STATOR \& SLIDER .................................................. 18 


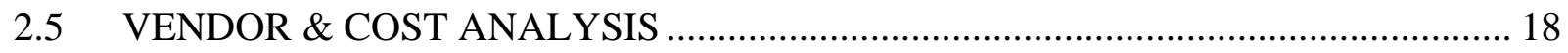

3 CONCLUSION AND RECOMMENDATIONS .................................................. 19

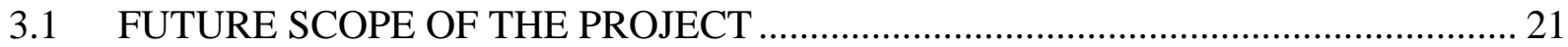

3.2 RECOMMENDATIONS FOR SEQUENCING …............................................ 21

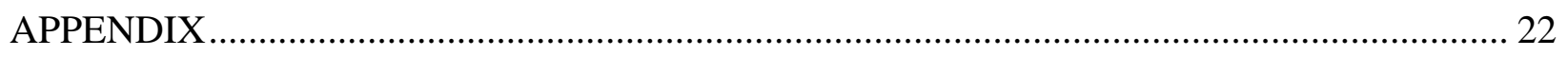

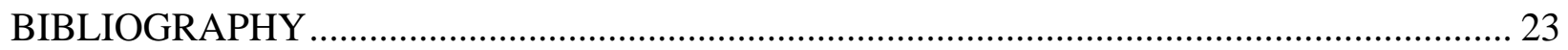




\section{LIST OF TABLES}

Table 1 List of items used in the project with product website links ...................................... 7

Table 2 Technical Data of Linear Motor (stator)[7] ......................................................... 8

Table 3 Mechanical Data of slider[8] ............................................................................... 9

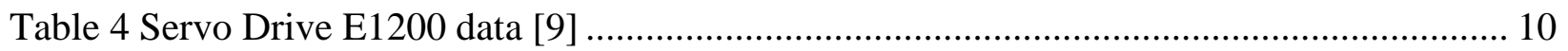

Table 5 Trailing Chain Cable KS03-W-Fe/K-2 data[11] ..................................................... 12

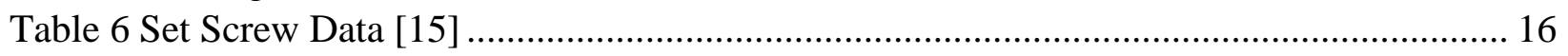

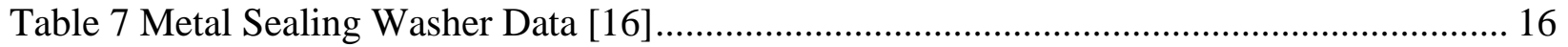

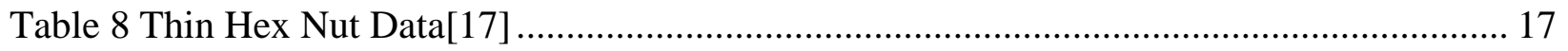

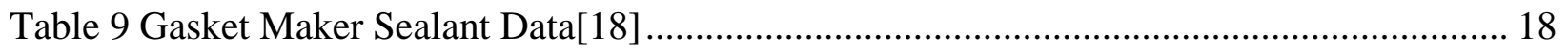




\section{LIST OF FIGURES}

Figure 1 Pneumatic System TSS used by Changshu Institute of Technology [1] ...................... 1

Figure 2 Pneumatic system with piston configuration used by University of Duisburg[2].......... 2

Figure 3 Multiple Probe system using stepper motor used by University of Toronto [3] ............. 3

Figure 4 Electric Thermophoretic sampling device using linear motor [4] ................................ 3

Figure 5 Designed thermophoretic sampling device for our project ........................................ 4

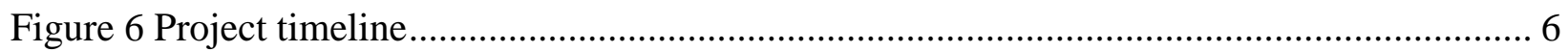

Figure 7 Linear Motor (Stator): PS02-23Sx80F-HP-K[7] .................................................... 8

Figure 8 CAD drawings of the linear motor (Stator): PS02-23Sx80F-HP-K[7] ....................... 8

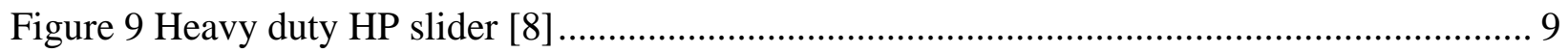

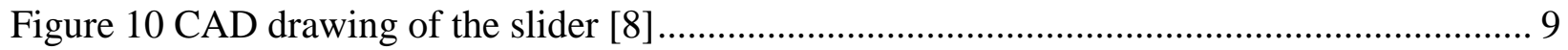

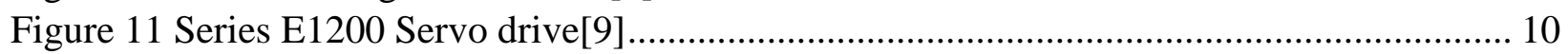

Figure 12 Ilustrative Diagram of Servo drive E1200 with dimensions[9]............................. 11

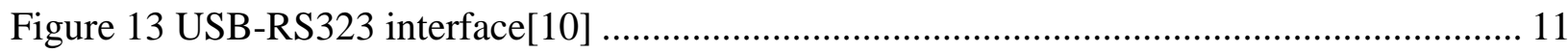

Figure 14 Trailing chain cable KS03-W-Fe/K-2[11] .......................................................... 12

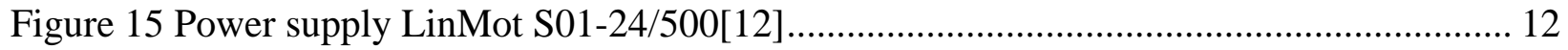

Figure $163 \mathrm{~mm}$ carbon coated copper grid with 200 mesh [13] ............................................ 13

Figure 17 Self-locking Tweezer to hold TEM-Micro grid [14] .............................................. 13

Figure 18 CAD drawings of tweezers holder with dimensions ............................................... 14

Figure 19 Tweezers holder assembly with setscrew, washer and nut.................................... 15

Figure $20 \mathrm{CAD}$ dtawings of set screws with dimensions[15] ............................................. 16

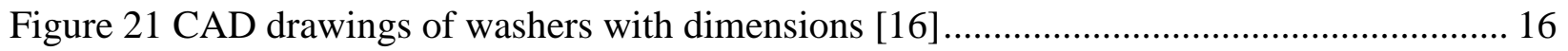

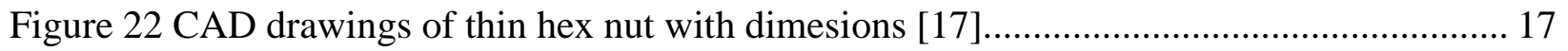

Figure 23 Gasket Maker Sealant, Permatex 800022, 3 oz. Tub [18] ...................................... 17

Figure 24 Lubricant LU02-50[19] ..................................................................................... 18

Figure 25 Thermophoretic sampling system all components .............................................. 19

Figure 26 Assembled design of tweezer holder, slider and stator ........................................ 20

Figure 27 Fully assembled design of thermophoretic sampling system ................................. 20

Figure 28 First design iteration of tweezer holder not easy to be fabricated ............................. 22

Figure 29 Drawing of first design iteration of a tweezer holder............................................. 22 


\section{INTRODUCTION}

The project objective is to design a thermophoretic sampling system (TSS) to collect soot particles using transmission electron microscope (TEM) micro grid in different fuel flames. This system is like a robotic arm with two degrees of freedom motion. One is the linear motion front $\&$ back and other is rotational, when the system needs a $90^{\circ}$ degree rotation. This system is integrated to a burner system where the burner can move up and down because of which TSS complexity reduced to two degree of freedom. The main design objective was to achieve an ultra high-speed stroke where the system can achieve a residue time for collecting soot particle that can vary from $3 \mathrm{~ms}$ to $100 \mathrm{~ms}$. It is imperative at no point the soot collected on micro grid is neither too less nor fully over loaded. Emitting soot depends on the fuel properties hence the design should have a capability to alter the residue time. In order to achieve this kind of high-speed stroke we needed a LinMot liner motor that can generate a force of at least $65 \mathrm{~N}$ that can also move with a speed of at least $7 \mathrm{~m} / \mathrm{s}$.

\subsection{LITERATURE REVIEW}

After looking at the existing literature, we were able to identify three systems; the first system is a pneumatic system, the second system is a multi-probe system using stepper motor and the last system is an electric system using a linear motor.

\subsubsection{PNEUMATIC SYSTEM ARCHITECT}

Changshu Institute of Technology, China, used a system that needed a standalone N2 cylinder

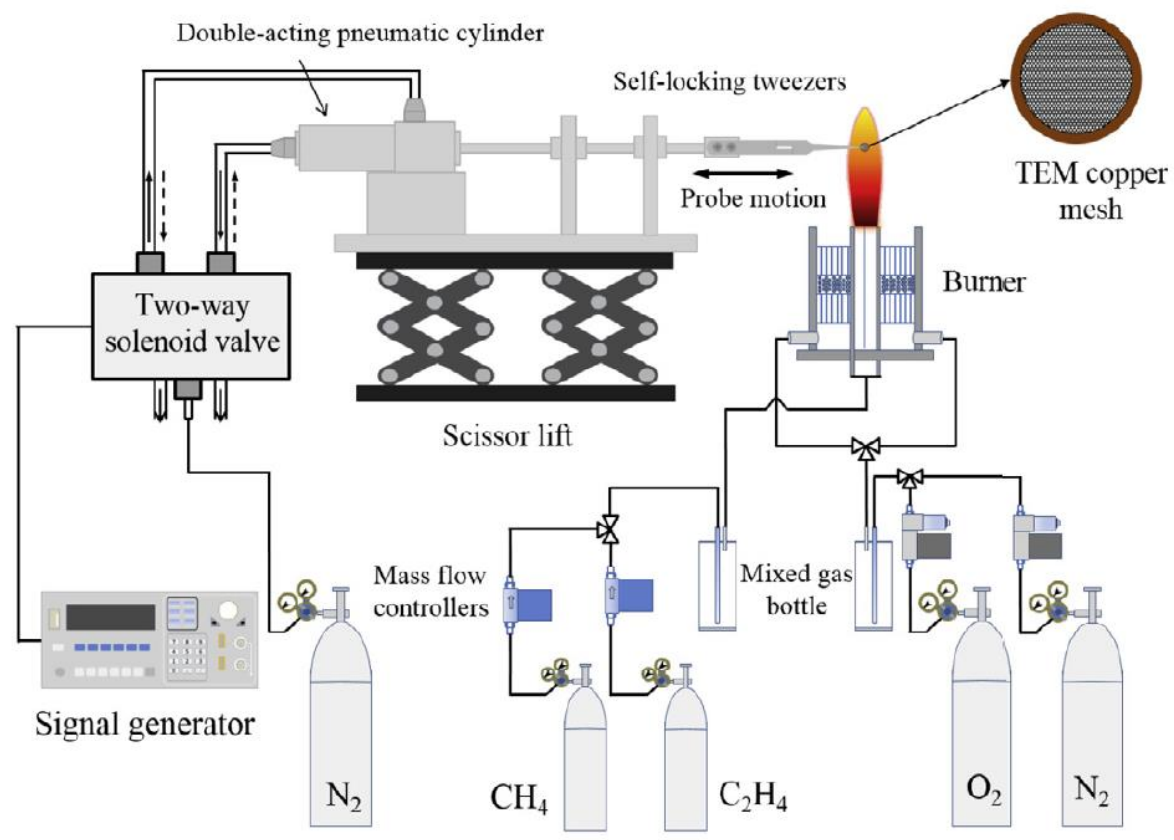

Figure 1 Pneumatic System TSS used by Changshu Institute of Technology [1] 
for operating TSS along with the other cylinders for combustion process[1], but what we observed that this pneumatic system design was only able to achieve a sampling residence time of $37 \mathrm{~ms}$ at 10bar[1]

The other pneumatic system that was researched was used by the University of Duisburg, Germany, which was a much more complicated system using a piston configuration but still it can only achieve residue time with a range from 67 to $1873 \mathrm{~ms}$ [2]. Our design objective is to achieve ultra high-speed stroke with a residue time of $3 \mathrm{~ms}$ which cannot be achieved with these designs.

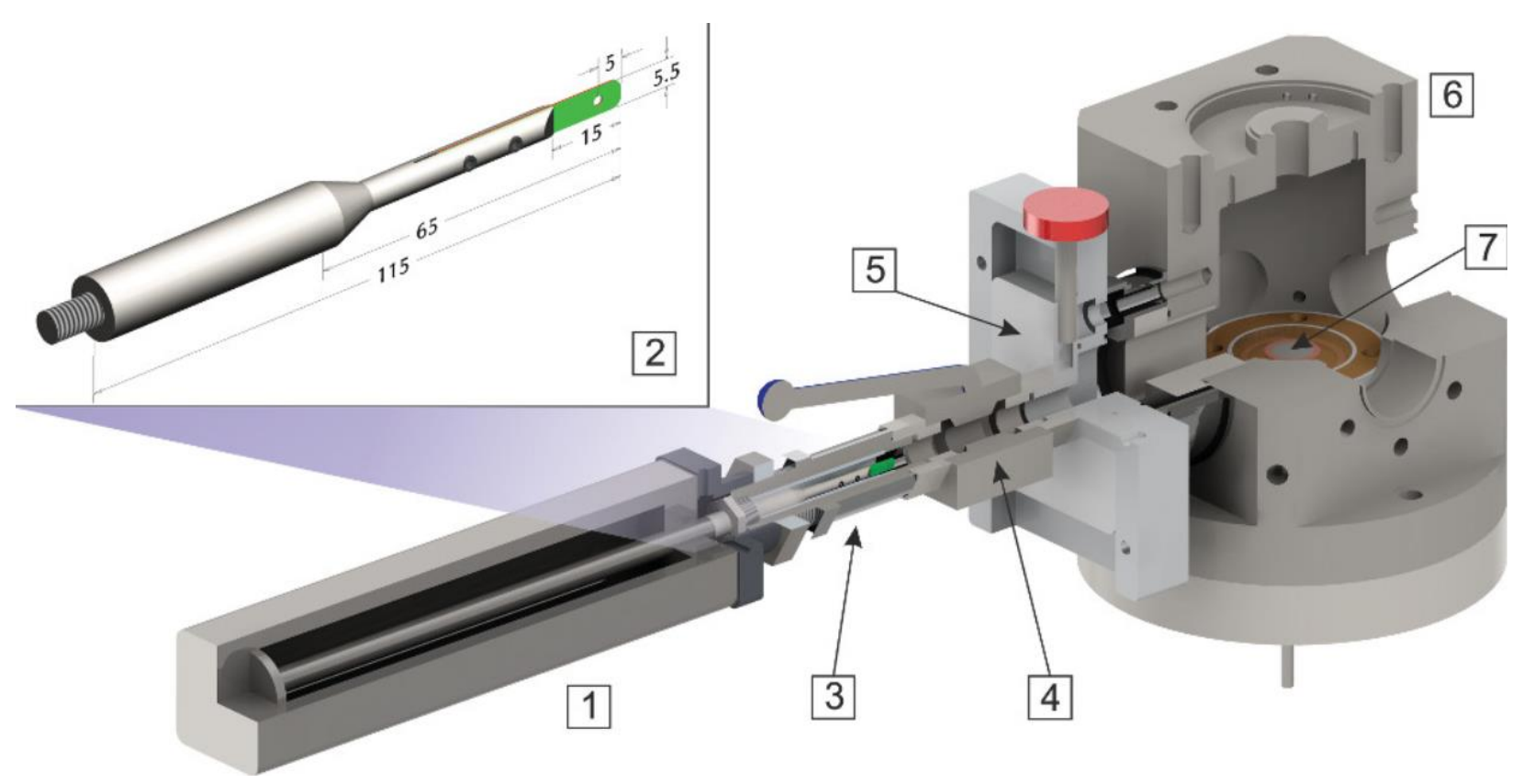

Figure 2 Pneumatic system with piston configuration used by University of Duisburg[2]

This system also consists of pneumatic cylinder which could generate a maximum force of $612 \mathrm{~N}$ at 6 bar and $1181 \mathrm{~N}$ at 10 bar pressure. The burner configuration of this system is different from our existing design. This design was not a consideration for our project.

\subsubsection{MULTI-PROBE SYSTEM}

The University of Toronto designed a sophisticated system with a multi-probe architect[3] which is driven by a stepper motor, where multiple samples can be taken at different intervals of time. This configuration has precision control with a sampling residue time of $2.6 \mathrm{~ms}$, which is also capable of collecting 10 samples in a single run. This system was designed for a high-pressure chamber where samples can be collected in laminar diffusion flames up to $100 \mathrm{~atm}$. This system has the sampling circular disc, attached to a gear box with 10:1 


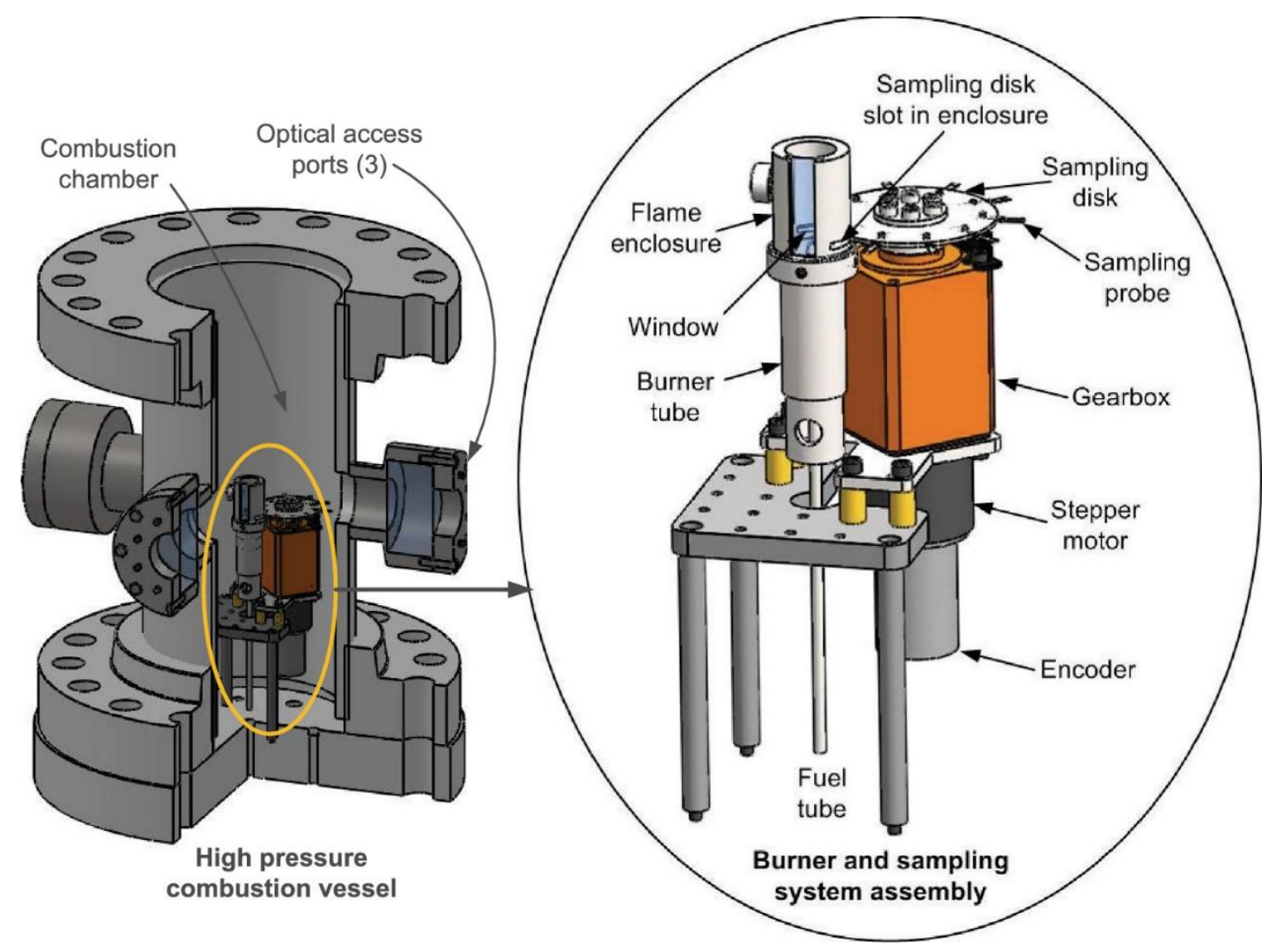

Figure 3 Multiple Probe system using stepper motor used by University of Toronto [3]

\subsubsection{LINEAR MOTOR SYSTEM}

The Review of Scientific Instruments Journal published a paper on an electric thermophoretic sampling device in Dec 2016, and this device used a linear motor from LinMot[4]

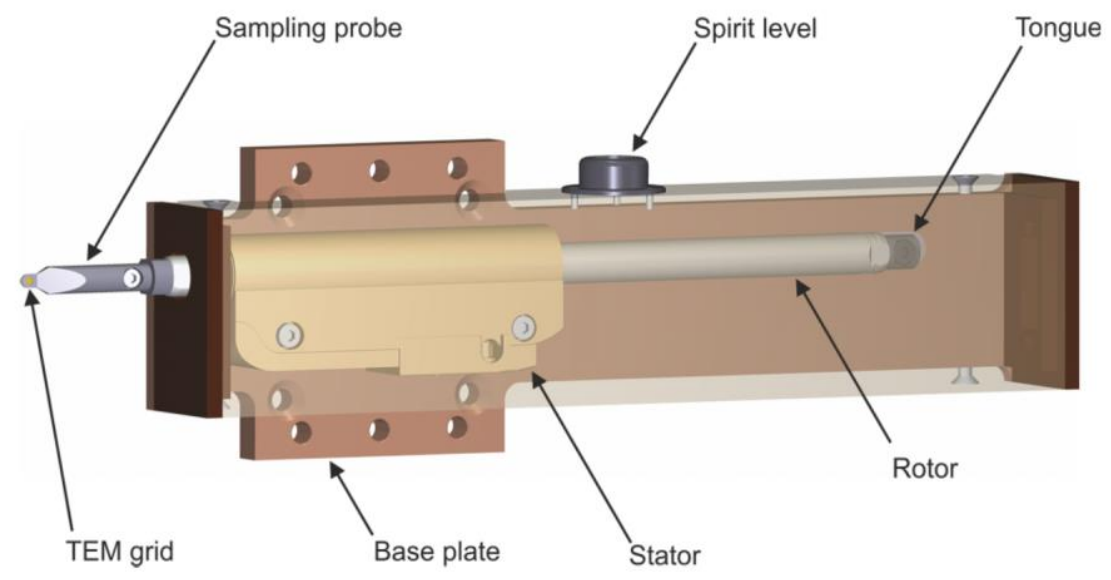

Figure 4 Electric Thermophoretic sampling device using linear motor [4]

This system consists of an electric motor connected to an electronic servo drive and a power supply. Servo drive helps the motor to operate across its force and velocity ranges according to the 
inputted instruction in the program. Path, speed, orientation can be sequenced using the program available with servo drive during the configuration of linear motor. Maximum speed achieved by the motor is one of the key design parameters that is directly translated into residue time. Speed and position of the slider can be easily altered as per the experiment requirement with help of a software associated with servo drive and motor.

This electric design architect inspired us to make similar system as it is very easy to construct and would meet our design requirements. Its also easy to vary the speed of the stroke using the software associated with the motor and the servo drive by which residue time can be changed. Our experimental setup is made to test different fuels, based on fuel properties time required to the collect the soot varies. Having an option to adjust the stroke speed would enable the system to operate at required residue time varying from $3 \mathrm{~ms}$ to $100 \mathrm{~ms}$. Hence, we came up with a similar design as shown in Figure 5 following chapter would discuss the design in detail.

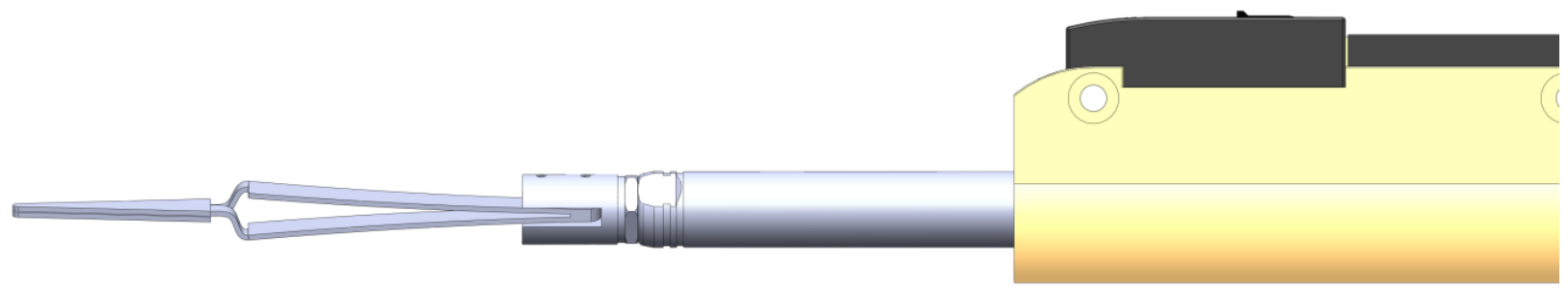

Figure 5 Designed thermophoretic sampling device (TSD) for our project

\subsection{INTRODUCTION TO SOOT}

Our main objective is to collect soot in burning flames of different fuel. In this project, we designed a thermophoretic sampling device to do the same. In layman language, the back carbon that is formed on a spoon when it is placed over the candlelight is called soot. It is sticky and can be seen on the walls of all exhaust pipes and chimneys. It is formed as a by-product as a result of incomplete combustion of hydrocarbon fuel. Soot gives luminosity to the flames for example yellow flickering glow of a candlelight, this phenomenon has triggered fascination to some of the greatest minds in the past[5]. But soot is not considered to be a good by-product in modern science and technology. Emitted soot has serious implications on human health, environment and climate change. Health implications due to soot is dated back to Aristotle, when he suspected the abortions were caused by "the smell of the smouldering wick of a candle" [6]. The hazards are not just limited to human health; soot is the second most warming agent after $\mathrm{CO}_{2}$ that is responsible for global warming [5]. Soot also has its fair share in diminishing the agricultural crops due to the inhibition of light and its effects on livestock.

One of the best ways to improve the understanding of soot formation is by conducting experiments in labs with different fuel mixtures. We can study soot formation by altering the fuel mix compositions at the same experimental conditions such as temperature, pressure and strain rate, 
and applying decomposition studies and numerical simulation could lead to significant insights. These insights could significantly contribute to the data base of fuel blends.

The objective of our total experimental set-up is to find soot volume fraction by using the line of sight of attenuation (LOSA) an optical diagnostic technique. 


\section{PROJECT OUTLINE}

\subsection{OBJECTIVE}

As we started the project, the main object was to achieve the $3 \mathrm{~ms}$ stoke residue time and to keep the cost of the project fairly low, and a less complicated setup and operation.

\subsection{TIMELINE OF THE PROJECT FROM AUGUST 2019 TO JANUARY 2020}

The project started with a literature review on soot, then followed by a study on the different thermophoretic sampling devices (TSD) that are available. We proceeded to go with an electric TSD design. The secondary research started with finding the right components in the market and at the same time, requesting for quotations from different vendors for the same components. The secondary research was done to find the right linear motor(stator), slider, servo drive, trailing chain cable, power supply, lubricant, USB interface converter, tweezers, set screws, washers, thin hex nuts, gasket sealants and to design a tweezer holder.

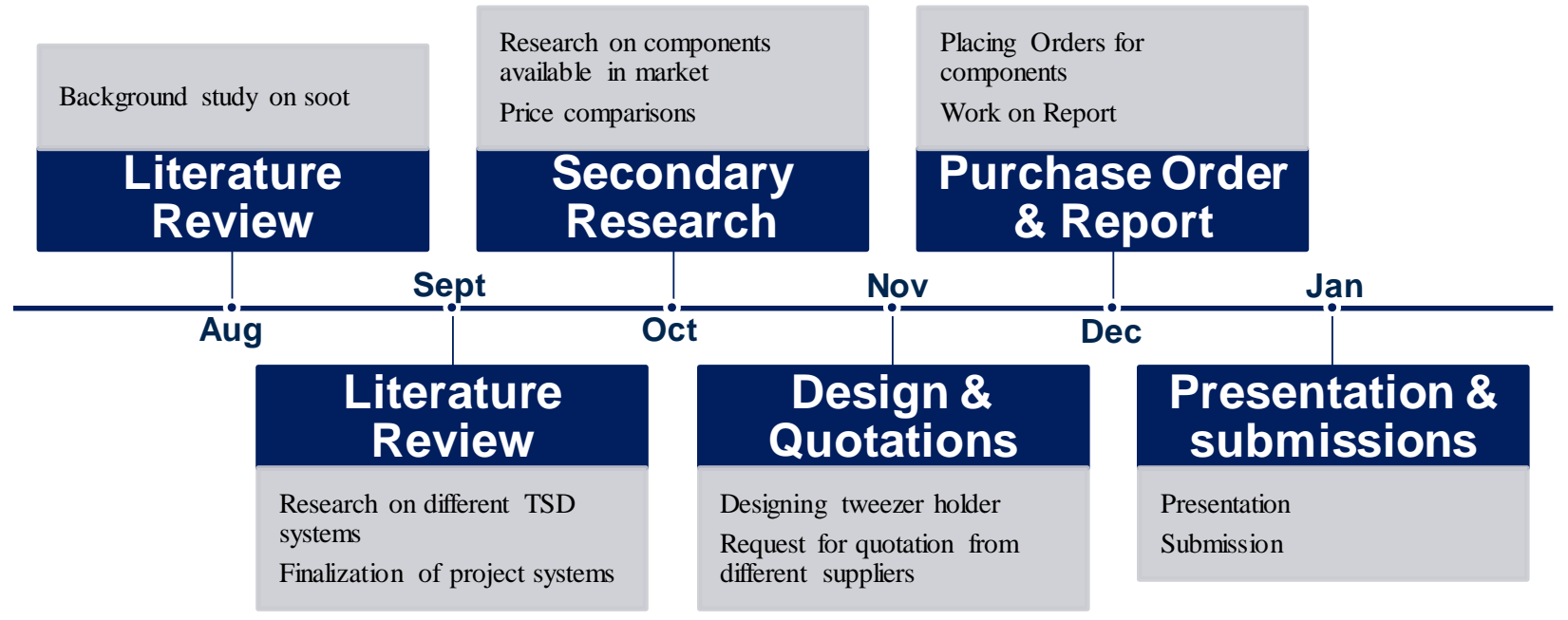

Figure 6 Project timeline

In addition, a cost analysis was performed on the component's prices received from multiple vendors. Quotation price of every vendor is compared to other vendors and websites and it was narrowed down to a vendor named Westburne in Mississauga. The Westburne quote was almost $15 \%$ lower to any other vendor in the market across North America for the major components. Then we placed an order with McMaster-Carr (US) for washers, setscrews, nuts and gasket. We 
shortlisted Structure Probe, Inc (US) as vendor for TEM-grids and placed an order with them for tweezers.

After completing the secondary research, we realized that we needed to design a tweezer holder which can fit with the slider that goes into the linear motor. Hence, we designed a tweezer holder and placed an order to machine the bit we needed. We chose to go with aluminum as the material of the tweezer holder to keep the weight of the fabricating bit at the lower end. As there is a penalty with weight, that might decrease the speed of retraction. We needed to also lower the weight. Simultaneously, we searched for the washers, setscrew and the gasket that is needed to make the holder to grip firm to the slider and tweezer. Then things progressed to making of the formal report and presentation. All these events spread were across a span of 6 months as shown in the Figure 6

\subsection{LIST OF ITEMS PURCHASED/SELECTED FOR THE PROJECT}

\begin{tabular}{|l|l|l|l|}
\hline S.No & $\begin{array}{l}\text { Part } \\
\text { Number }\end{array}$ & Product & Link \\
\hline 1 & $0150-1285$ & Liner Motor (stator) & $\underline{\text { https://shop.LinMot.com/E/product/0150-1285 }}$ \\
\hline 2 & $0150-1519$ & Slider & $\underline{\text { https://shop.LinMot.com/E/product/0150-1519 }}$ \\
\hline 3 & $0150-1771$ & Servo drive & $\underline{\text { https://shop.LinMot.com/E/product/0150-1771 }}$ \\
\hline 4 & $0150-2187$ & Trailing chain cable & $\underline{\text { https://shop.LinMot.com/E/product/0150-2187 }}$ \\
\hline 5 & $0150-2480$ & Power supply & $\underline{\text { https://shop.LinMot.com/E/product/0150-2480 }}$ \\
\hline 6 & $0150-2473$ & USB converter & $\underline{\text { https://shop.LinMot.com/E/product/0150-2473 }}$ \\
\hline 7 & SN5AP-XD & Tweezer & $\underline{\text { https://www.2spi.com/item/sn5ap-xd/ }}$ \\
\hline 8 & $92605 \mathrm{~A} 043$ & Set screw & $\underline{\text { https://www.mcmaster.com/92605a043 }}$ \\
\hline 9 & $97725 \mathrm{~A} 510$ & Washer & $\underline{\text { https://www.mcmaster.com/97725a510 }}$ \\
\hline 10 & $90710 \mathrm{~A} 037$ & Thin Hex Nut & $\underline{\text { https://www.mcmaster.com/90710a037 }}$ \\
\hline 11 & $3520 \mathrm{C}-\mathrm{CF}$ & TEM-Micro grid & $\underline{\text { https://www.2spi.com/item/3520c-mb/ }}$ \\
\hline 12 & In-house & Tweezer holder & In-house Design \\
\hline 13 & $7535 \mathrm{~A} 12$ & Gasket Sealant & $\underline{\text { https://www.mcmaster.com/7535a12 }}$ \\
\hline 14 & $0150-1954$ & Lubricant & $\underline{\text { https://shop.LinMot.com/E/product/0150-1954 }}$ \\
\hline
\end{tabular}

Table 1 List of items used in the project with product website links

\subsection{COMPONENTS DESCRIPTION}

\subsubsection{LINEAR MOTOR (STATOR)}

After a significant amount of secondary research, we finally zeroed down on LinMot PS0223Sx80F-HP-K as the linear motor that we would use for our project mainly because of the highspeed stroke we can achieve using this motor. PS02-23Sx80F-HP-K can achieve a stroke speed of $7.3 \mathrm{~m} / \mathrm{s}$ with force of $67.1 \mathrm{~N}$ at $32 \mathrm{~A} / 72 \mathrm{VDC}$. Important technical data is given in Table 2 as followed. Deciding the motor is a key element for the project by which other components like the electronic drive and power supply were chosen in accordance to the stator specifications. 


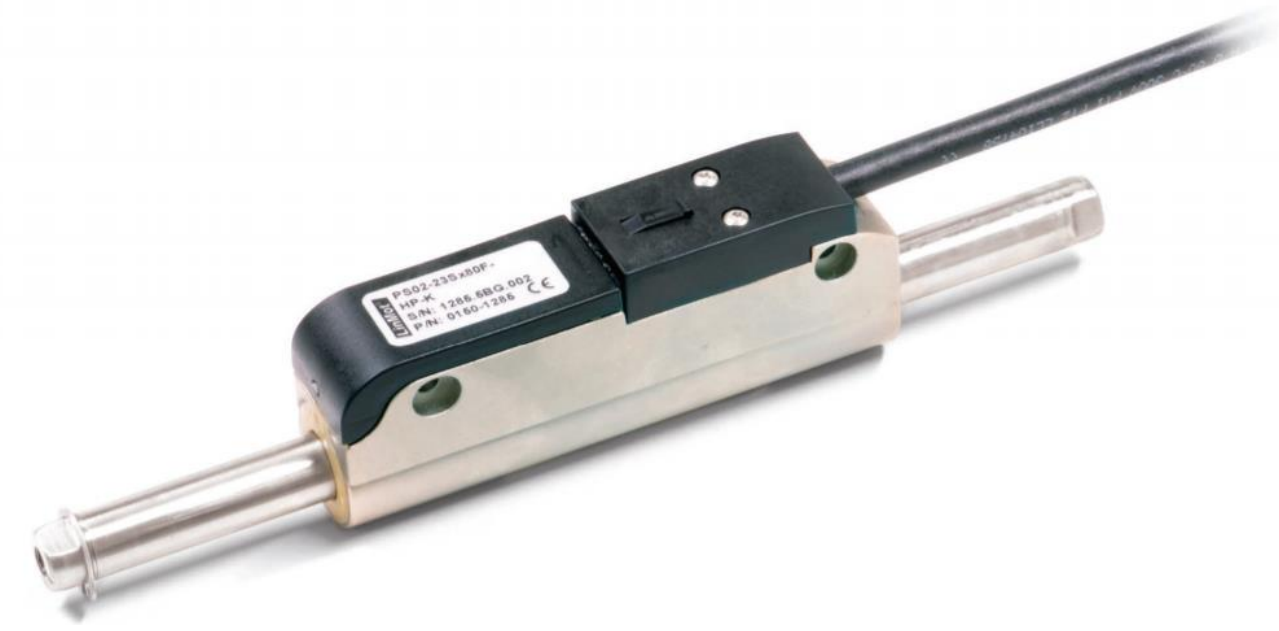

Figure 7 Linear Motor (Stator): PSO2-23Sx80F-HP-K[7]

\begin{tabular}{|l|l|l|l|}
\hline Max. Stroke Length & $720 \mathrm{~mm}$ & Slider Dia. & $12 \mathrm{~mm}$ \\
\hline $\begin{array}{l}\text { Max. Force at } \\
\text { 72VDC }\end{array}$ & $67.1 \mathrm{~N}$ & Slider Length & $130-850 \mathrm{~mm}$ \\
\hline $\begin{array}{l}\text { Max. Velocity at } \\
\text { 72VDC }\end{array}$ & $7.3 \mathrm{~m} / \mathrm{s}$ & Slider Mass & $90-700 \mathrm{~g}$ \\
\hline Stator Dia. & $23 \mathrm{~mm}$ & Max. Winding Temp & $120^{\circ} \mathrm{C}$ \\
\hline Stator Mass & $245 \mathrm{~g}$ & IP Code & IP50 \\
\hline
\end{tabular}

Table 2 Technical Data of Linear Motor (stator)[7]
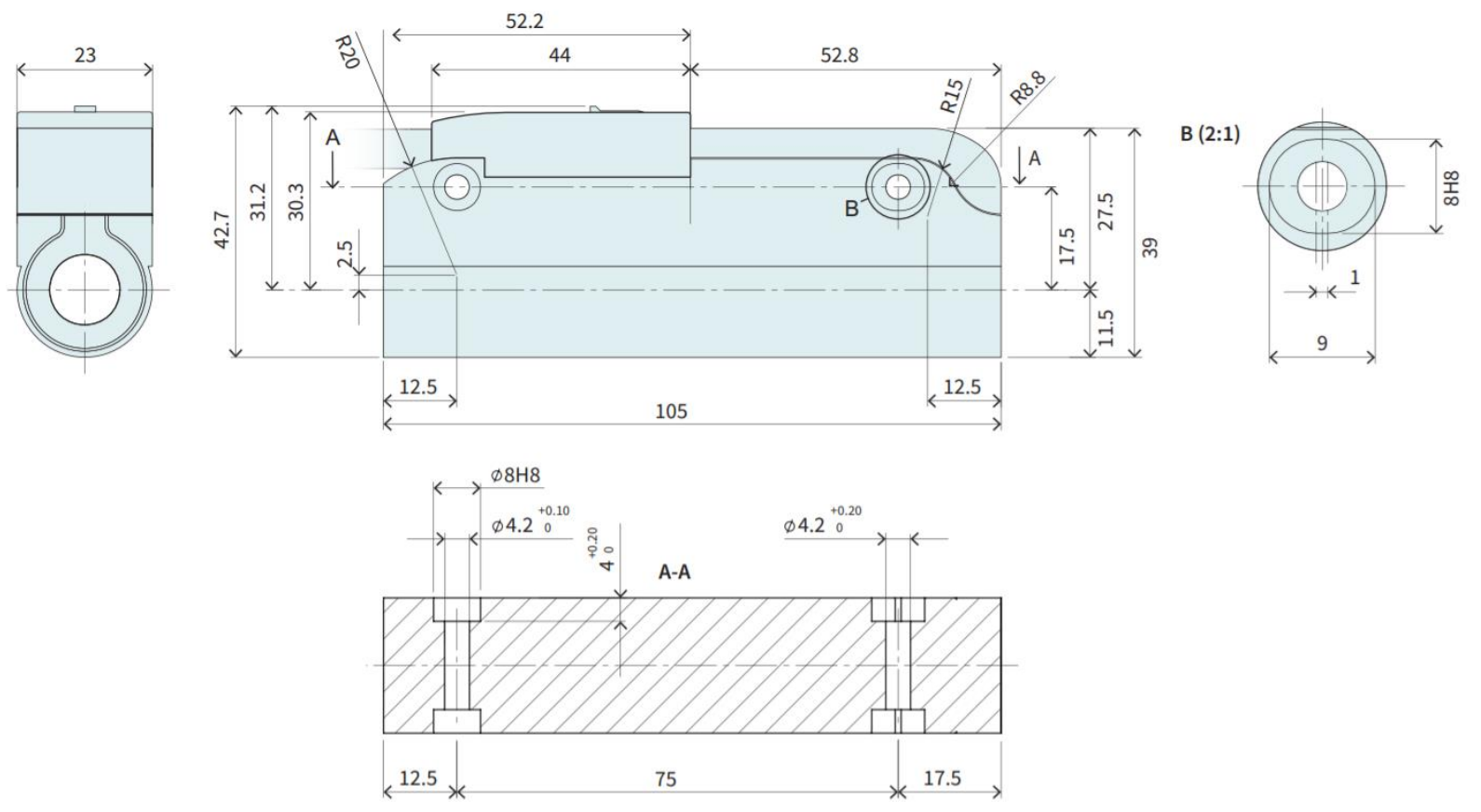

Figure 8 CAD drawings of the linear motor (Stator): PSO2-23Sx80F-HP-K[7] 


\subsubsection{SLIDER}

Other important decision to be taken for the project is the length of the sliders and the type of the slider that we need to decide between the slider with and without a bore. As we have no requirement for the bored slider which is twice as expensive compared to non bored slider, we chose to go with slider without the bore.

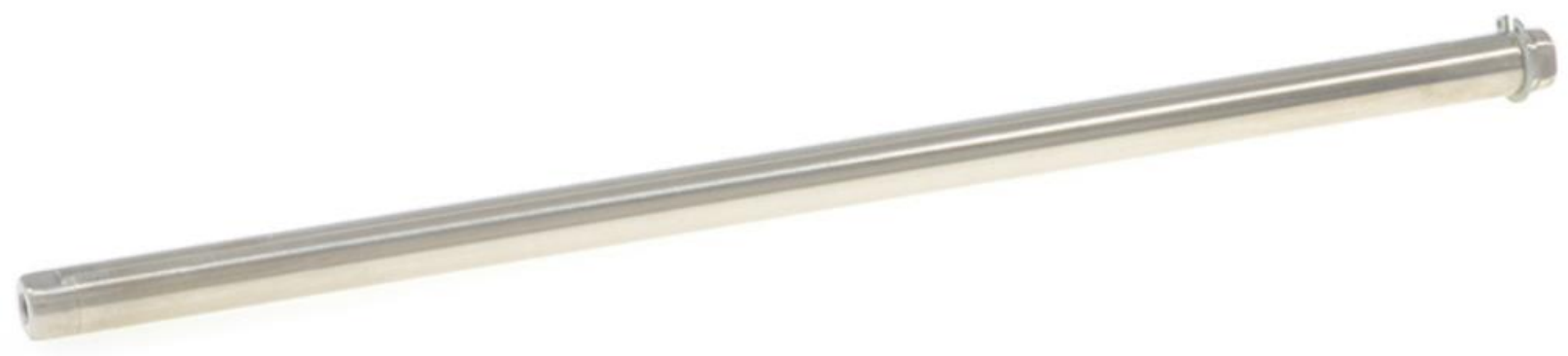

Figure 9 Heavy duty HP slider [8]

Deciding the length was the other task, as based on the project requirements that we had with us, we needed a stroke length of at least $5.59 \mathrm{~cm}(2.2 \mathrm{inch})$ above the burner. This is the distance between centre point of the burner up to initial point of the TSS, then clearance needed was $2 \mathrm{~cm}$, and the stator has a length of $10.5 \mathrm{~cm}$ that's the length of slider which is always inside the motor. Keeping the minimum requirements in mind $(5.49 \mathrm{~cm}+2 \mathrm{~cm}+10.5 \mathrm{~cm})$ and adding the scope for future requirements, we chose a length of $230 \mathrm{~mm}(23 \mathrm{~cm})$. One end of the slider has an M5 grove for attachment, where we designed an inhouse tweezer holder to fit this slider as show in Figure 19.

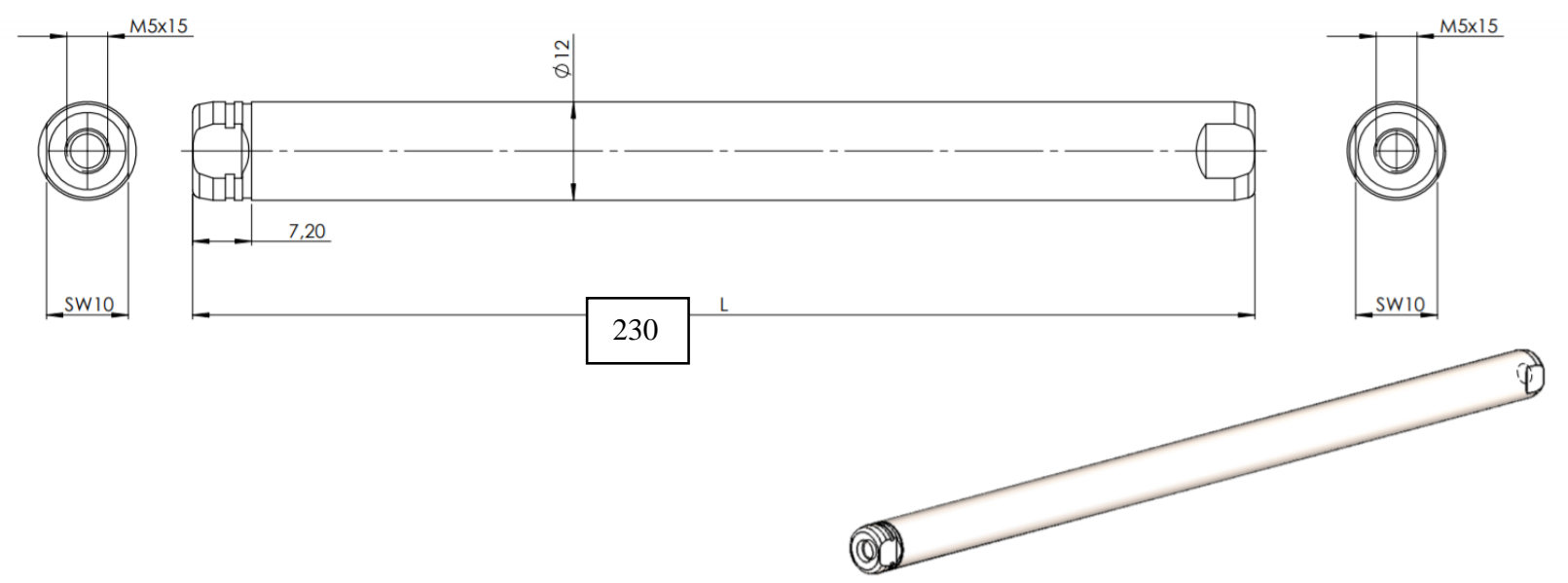

Figure 10 CAD drawing of the slider [8]

\begin{tabular}{|l|l|l|l|}
\hline Length & $230 \mathrm{~mm}$ & Mass & $180 \mathrm{~g}$ \\
\hline Dia. & $12 \mathrm{~mm}$ & Through bore & no \\
\hline
\end{tabular}

Table 3 Mechanical Data of slider[8] 


\subsubsection{SERVO DRIVE E1200}

The Servo Drive E1200 is a general-purpose drive that helps in integrating power stage with position resolution for rotary and linear motors. This drive is suitable in achieving our project objective, which is an ultra high-speed stroke with precision across the entire force and velocity range of the LinMot PS02-23Sx80F-HP-K motor. This servo drive work with both $24 \mathrm{~V} / 72 \mathrm{~V}$ power supply but giving the same motor current of 32A. The configuration and parameterization of E1200 is done via the ethernet interface, as this interface is widely used by the industries. Since w needed an USB interface, we also ordered a USB converter; refer to section 2.4.4. Using this drive, we wanted to achieve a linear stroke with a min. residue time of $3 \mathrm{~ms}$ and similar stroke at $90^{\circ}$ angle, by rotating the slider as required. The detailed data of the product can be obtained from the link in Table 1.

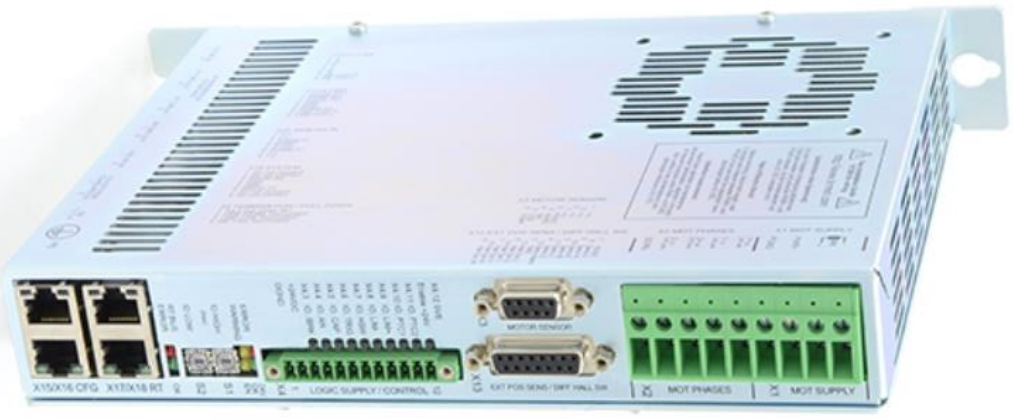

Figure 11 Series E1200 Servo drive[9]

\begin{tabular}{|l|l|l|l|}
\hline Motor supply & $24 . .72 \mathrm{VDC}$ & Analog Inputs 0..10V & 2 \\
\hline Motor Current & $32 \mathrm{~A}$ & Digital In \& outputs & 10 \\
\hline Interface & CanOpen, LinRS & Dimensions & $40 \times 270 \times 180 \mathrm{~mm}$ \\
\hline
\end{tabular}

Table 4 Servo Drive E1200 data [9] 


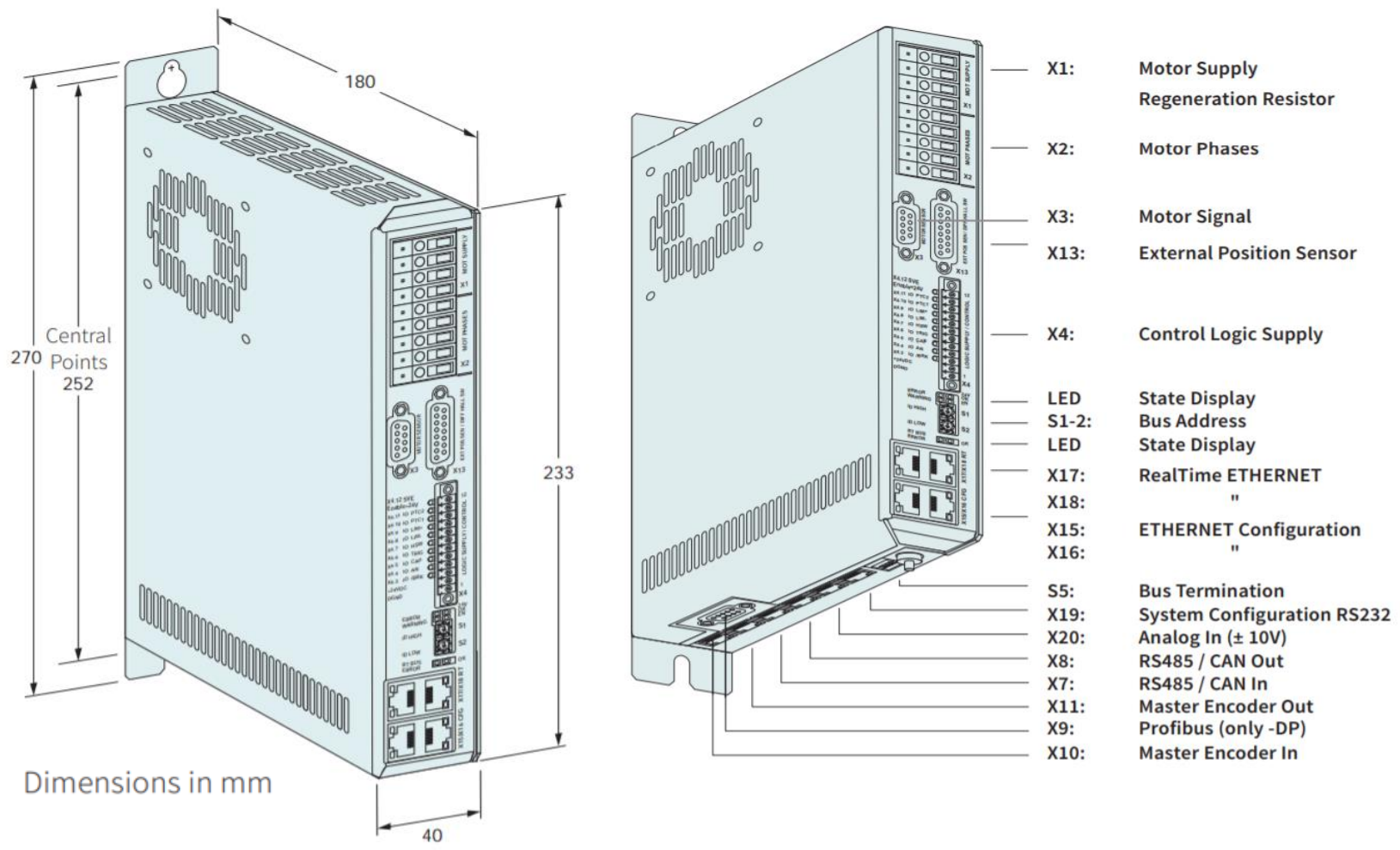

Figure 12 Ilustrative Diagram of Servo drive E1200 with dimensions[9]

\subsubsection{USB-RS232 CONVERTER}

This convertor helps in providing the galvanically isolate the RS232 interface to a PC or a laptop. Detailed data of the product can be obtained from the link in Table 1.

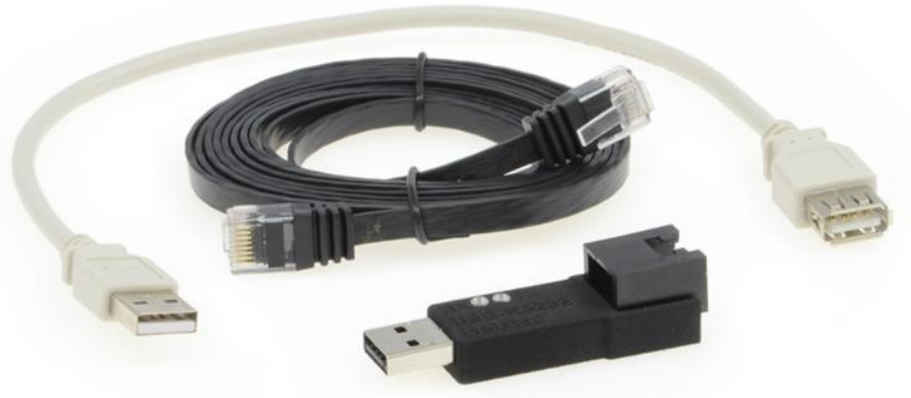

Figure 13 USB-RS323 interface[10] 


\subsubsection{TRAILING CHAIN CABLE (2M)}

This is a trailing chain cable of two meters that connects linear motor and servo drive E1200, including a K-connector with data as follows. Detailed data of the product can be obtained from the link in Table 1.

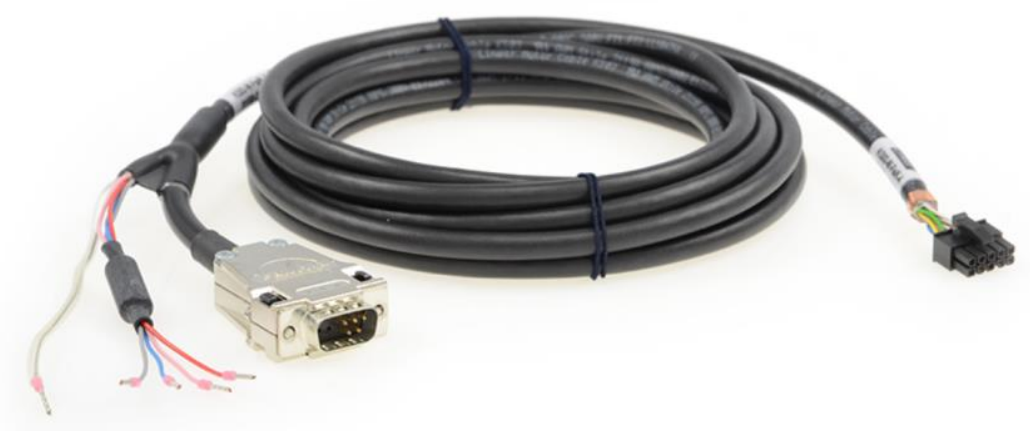

Figure 14 Trailing chain cable KSO3-W-Fe/K-2[11]

\begin{tabular}{|l|l|l|l|}
\hline Cable diameter & $6.7 \mathrm{~mm}$ & Cable weight & $64 \mathrm{~g} / \mathrm{m}$ \\
\hline Min. bend radius stationary & $25 \mathrm{~mm}$ & Temp. range & $-40 \ldots+80^{\circ} \mathrm{C}$ \\
\hline Min bend radius moving & $50 \mathrm{~mm}$ & Material according to & UL/CSA 300V \\
\hline
\end{tabular}

Table 5 Trailing Chain Cable KSO3-W-Fe/K-2 data[11]

\subsubsection{POWER SUPPLY}

The battery was other major decision we needed to consider as we had two variants
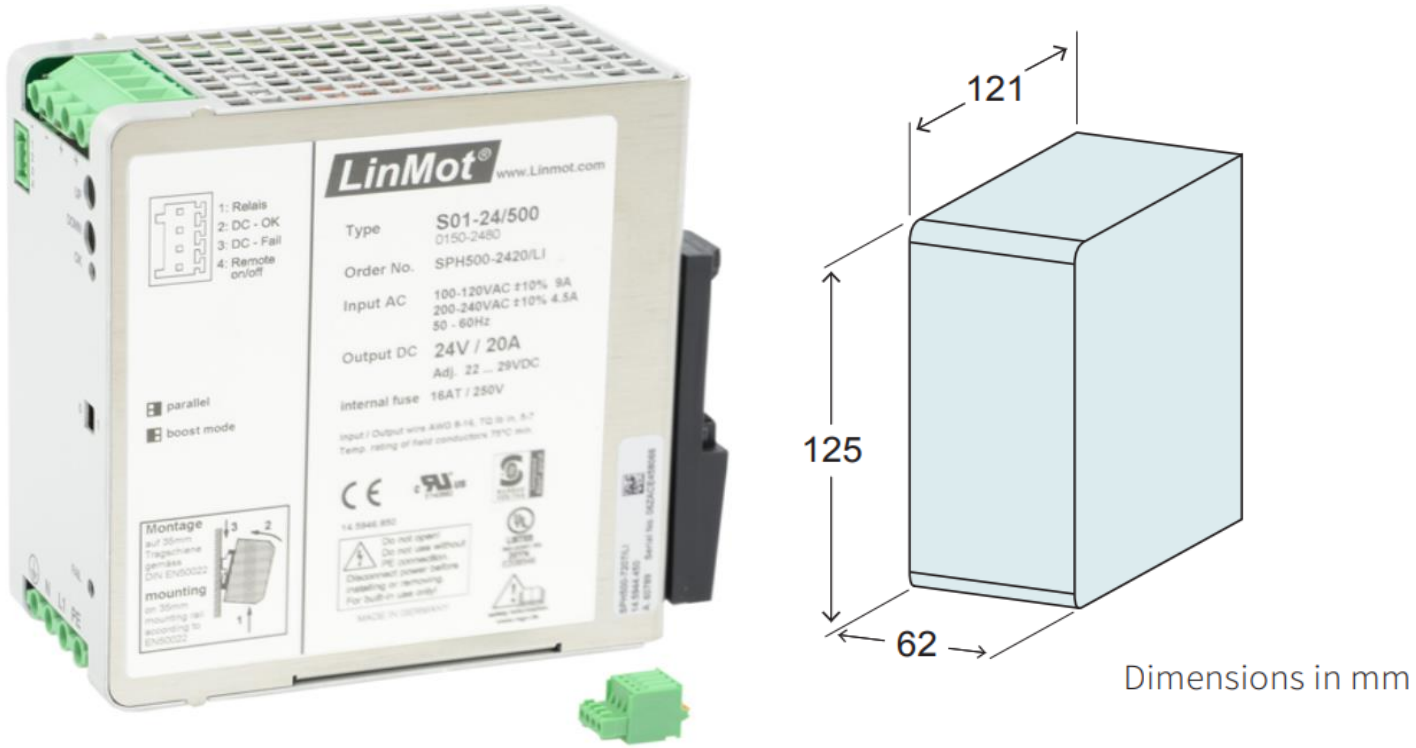

Figure 15 Power supply LinMot S01-24/500[12]

available for $500 \mathrm{~W}$ that works with the stator and the drive we selected. One variant is $72 \mathrm{~V}$ battery and the other variant was $24 \mathrm{~V}$. Keeping the safety considerations in mind, we have chosen the $24 \mathrm{~V}$ 
since the power output for the both is same. These batteries can be directly mounted to the wall or the variant we selected can be snapped to the DNI-rail of $35 \mathrm{~mm}$ with a diameter of 1 to $2.5 \mathrm{~mm}$.

\subsubsection{TEM-MICRO GRIDS}

The micro grid is used for collecting the soot from different fuel flames, which is the main objective of our experimental setup. Our project is to facilitate a set-up to collect soot from flames using a micro grid as the collector. We have shorted listed SPI supplies as the vendor for buying the TEM-micro grids. A carbon coated 3mm grid with 200 mesh is selected for our use as shown in Figure 16 below.

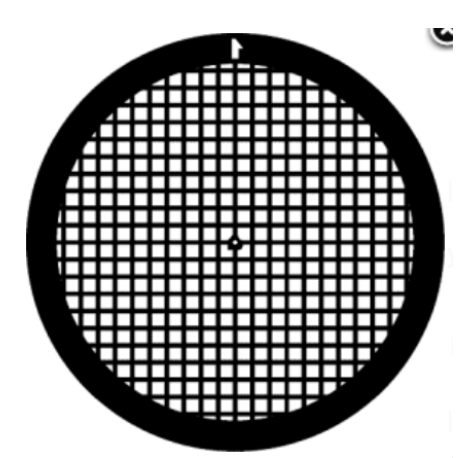

Figure $163 \mathrm{~mm}$ carbon coated copper grid with 200 mesh [13]

\subsubsection{TWEEZER}

A self-locking tweezer was chosen for holding the micro-grid, and this tweezer will hold the micro grid which goes into the tweezer holder that is designed in-house, as explained in 2.4.9. Using a tweezer for holding the micro grid was inspired by the design in the paper of Chu $\mathrm{H}, \mathrm{Han} \mathrm{W}$, Cao $\mathrm{W}[1]$ as depicted in Figure 1.

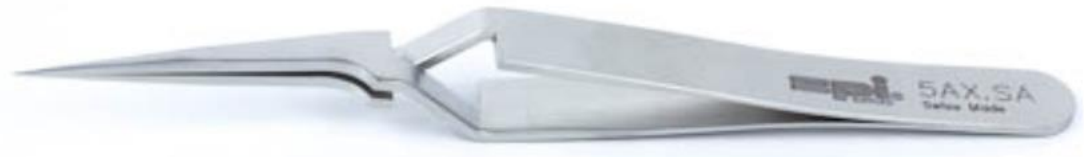

Figure 17 Self-locking Tweezer to hold TEM-Micro grid [14]

\subsubsection{TWEEZER HOLDER}

As the slider was having a M5 bore at one end, we needed to design a M5 screw bit that can hold a tweezer which in-turn holds the TEM-micro grid. The available dimension on the slider is M5 bore with a depth of $7.2 \mathrm{~mm}$. Hence, we designed a bit with M5 screw of $12 \mathrm{~mm}$ length that can go inside the slider along with a washer as show in Figure 21 and a nut in Figure 22. 
Using an additional hex nut on the threaded shaft of the bit is for giving an additional aid in tightening for the required orientation. Using the hex nut, we can freeze the orientation of tweezer holder angle as required (to make sure the angle is zero to the axis) and use its own threads on shaft for tightening. This design is inspired from motor bikes' rear-view mirror assembly that is commonly used in all motor bikes in India. Threaded M5 screw is $12 \mathrm{~mm}$ in length, which has enough clearance to use multiple washers and nuts. This design has two shafts with dia. 10mm and $5 \mathrm{~mm}$ attached concentrically with a total length of $22 \mathrm{~mm}$ as shown in Figure 18. This is a good design because it can be easily fabricated using one single rod of dia. $10 \mathrm{~mm}$ and length $22 \mathrm{~mm}$ on a lathe machine.

On the top and bottom of the 10mm circumference head, there are two M2 tapped holes as shown in the Figure 19. Set screws are passed through it and used to hold the tweezers in its place tightly. We order a liquid gasket as shown in Figure 23, that can be applied on the tweezer to form a thin layer of rubber to absorb vibrations and grip firmly in order to withstand the high-speed stroke action.
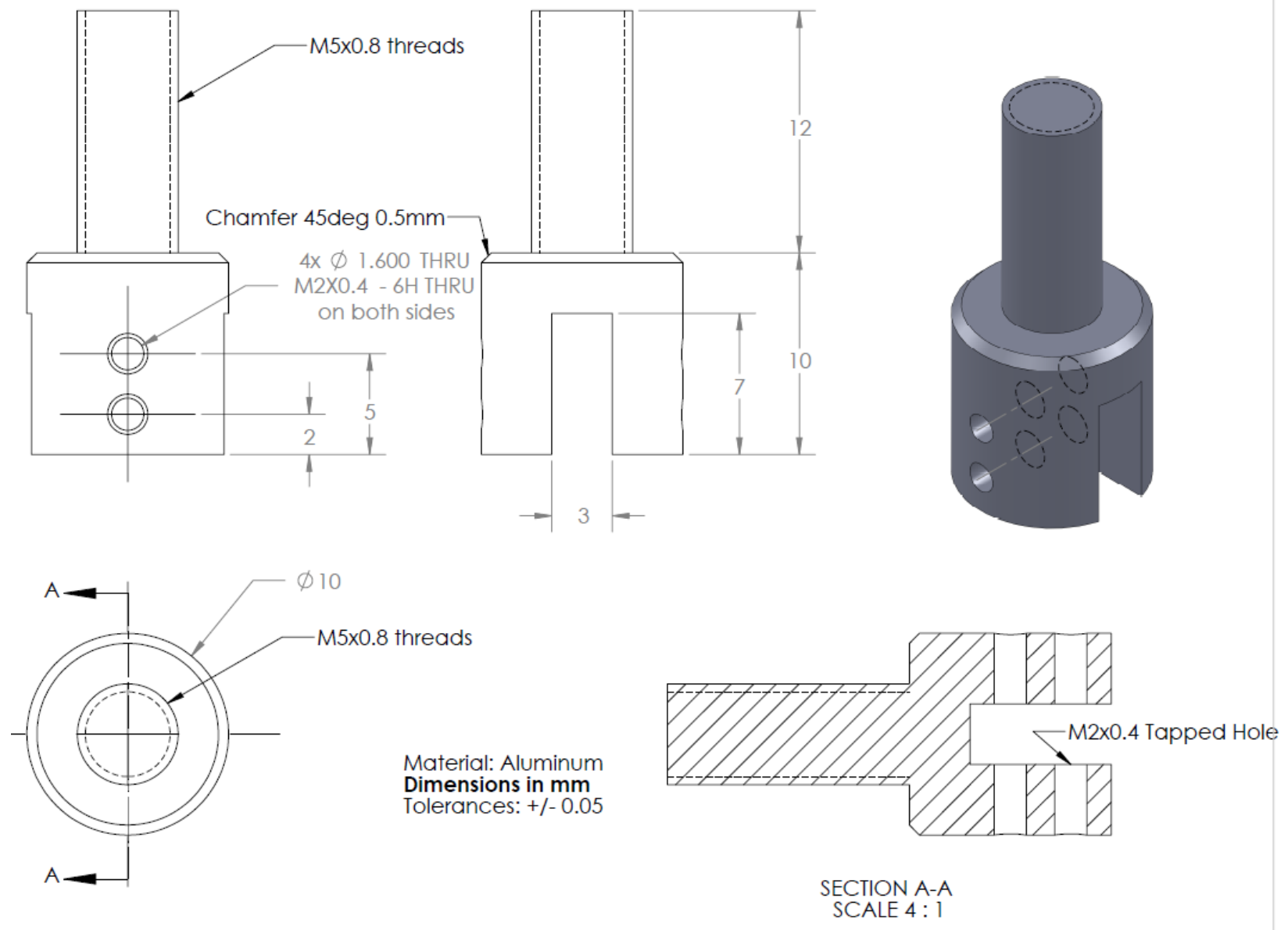

Figure 18 CAD drawings of tweezers holder with dimensions

The U slit in the tweezer holder as show in the Figure 19 is used for inserting the tweezer and then making it firm and tight using the set screw and gasket as previously mentioned. This design 
included engineering practicality at every step. The detachable tweezers mechanism is adopted so that we can change tweezers as required based on the need or when it is worn out. The liquid gasket sealer was chosen again for convenience.

Figure 19 shows the tweezer holder assembly and all the components that are included for assembly.

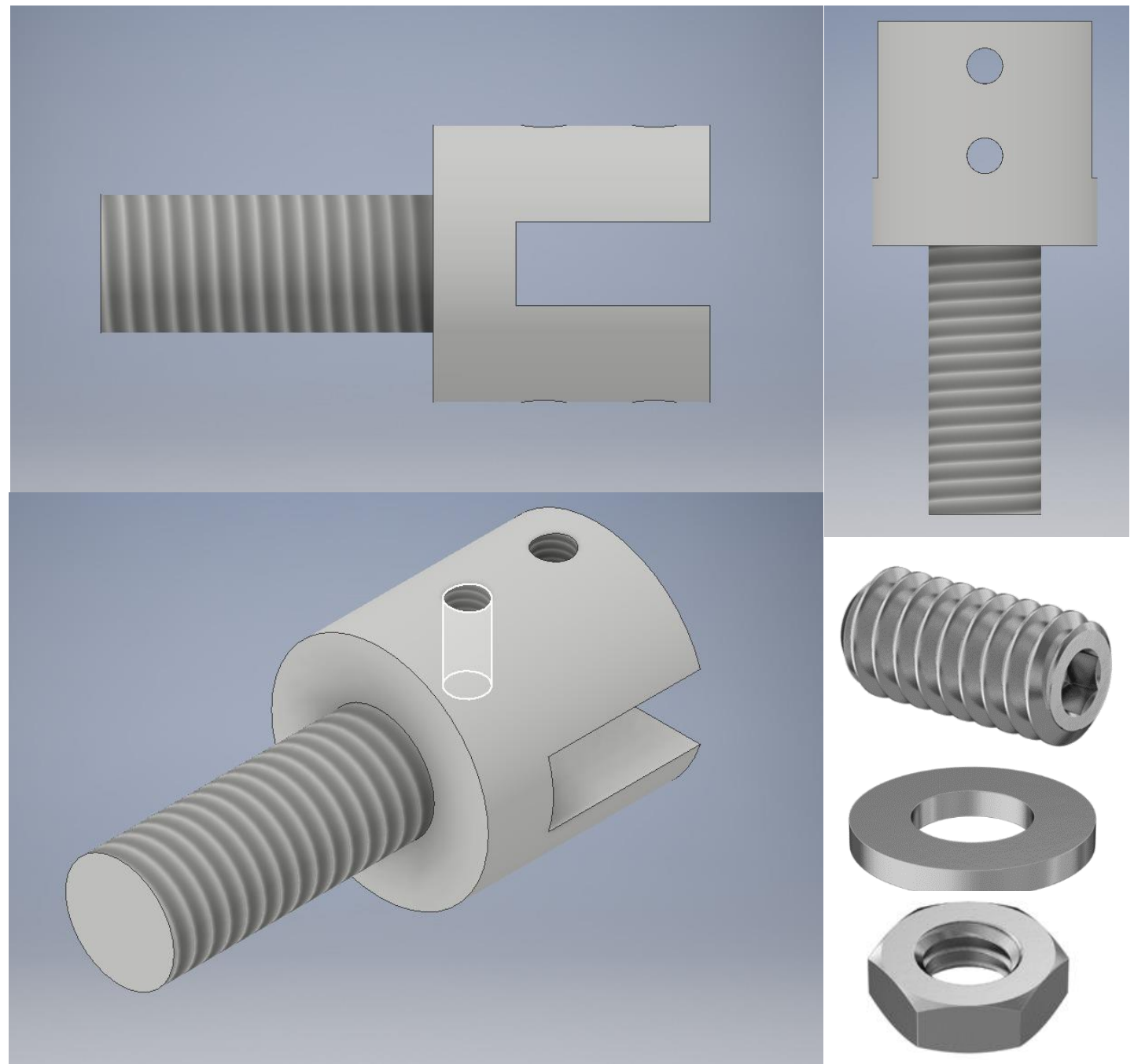

Figure 19 Tweezers holder assembly with setscrew, washer and nut.

\subsubsection{SET SCREW}

M2 threaded set screw with a length of $4 \mathrm{~mm}$ 

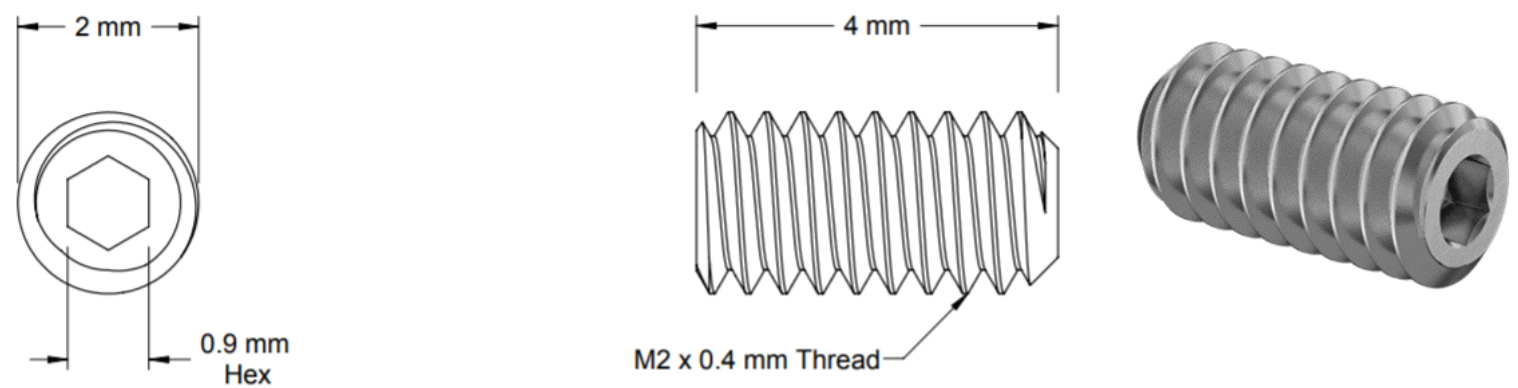

Figure 20 CAD dtawings of set screws with dimensions[15]

\begin{tabular}{|l|l|l|l|}
\hline Material & $18-8$ Stainless steel & Thread size & M2 \\
\hline Hardness & Rockwell B80 & Thread pitch & $0.4 \mathrm{~mm}$ \\
\hline Drive style & Hex & Length & $4 \mathrm{~mm}$ \\
\hline Spec. Met & DIN 913, ISO 4026 & Drive size & $0.9 \mathrm{~mm}$ \\
\hline
\end{tabular}

Table 6 Set Screw Data [15]

\subsubsection{METAL SEALING WASHER}

The washer to give extra grip to the hex nut and fill the clearance space.
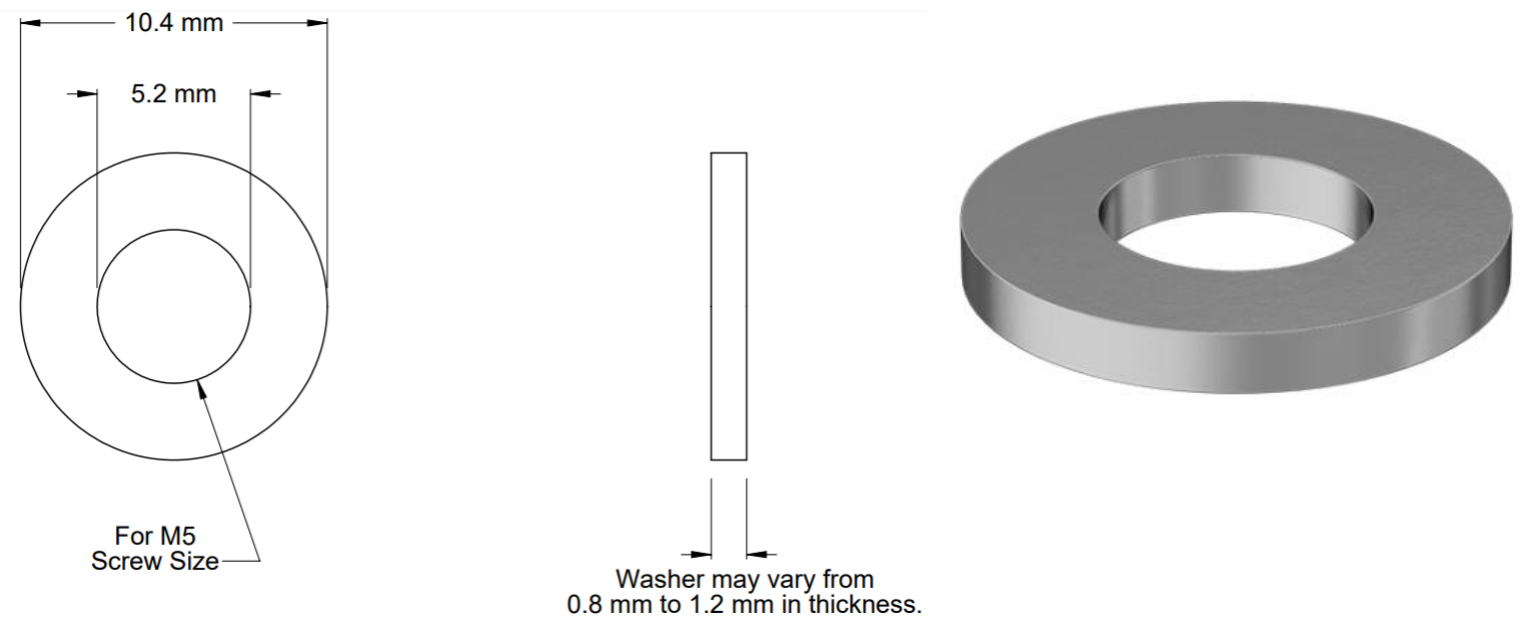

Figure 21 CAD drawings of washers with dimensions [16]

\begin{tabular}{|l|l|l|l|}
\hline Material & Copper & For Screw Size & M5 \\
\hline Thickness & $0.8-1.2 \mathrm{~mm}$ & OD & $10.4 \mathrm{~mm}$ \\
\hline Washer Type & flat & ID & $5.2 \mathrm{~mm}$ \\
\hline
\end{tabular}

Table 7 Metal Sealing Washer Data [16] 


\subsubsection{THIN HEX NUT}

This is used for aligning the orientation of tweezers holder with zero axis or as required as previously discussed in 2.4.9.
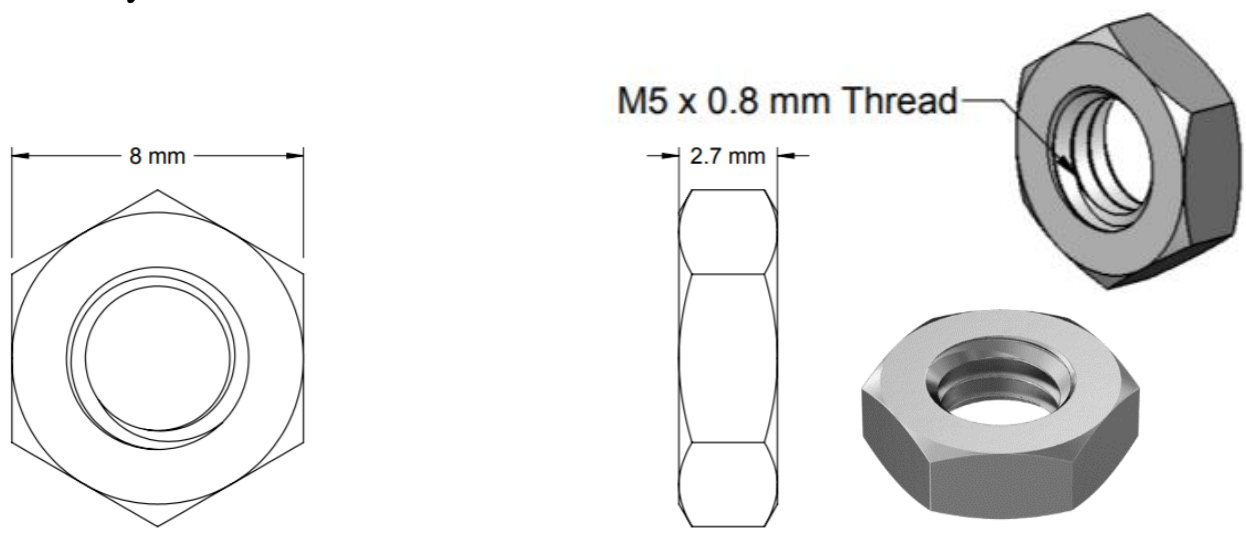

Figure 22 CAD drawings of thin hex nut with dimesions [17]

\begin{tabular}{|l|l|l|l|}
\hline Material & $18-8$ Stainless steel & Thread Size & M5 \\
\hline Nut Type & Hex & Thread Pitch & $0.8 \mathrm{~mm}$ \\
\hline Width & $8 \mathrm{~mm}$ & Thread Spacing & Coarse \\
\hline Height & $2.7 \mathrm{~mm}$ & Thread Direction & Right Hand \\
\hline Spec. Met & DIN 439B, ISO 4035 & Thread Fit & Class 6H \\
\hline
\end{tabular}

Table 8 Thin Hex Nut Data[17]

\subsubsection{GASKET MAKER SEALANT}

The gasket is chosen to act as a seal and also as a vibration absorbent between the tweezer and the tweezer holder.
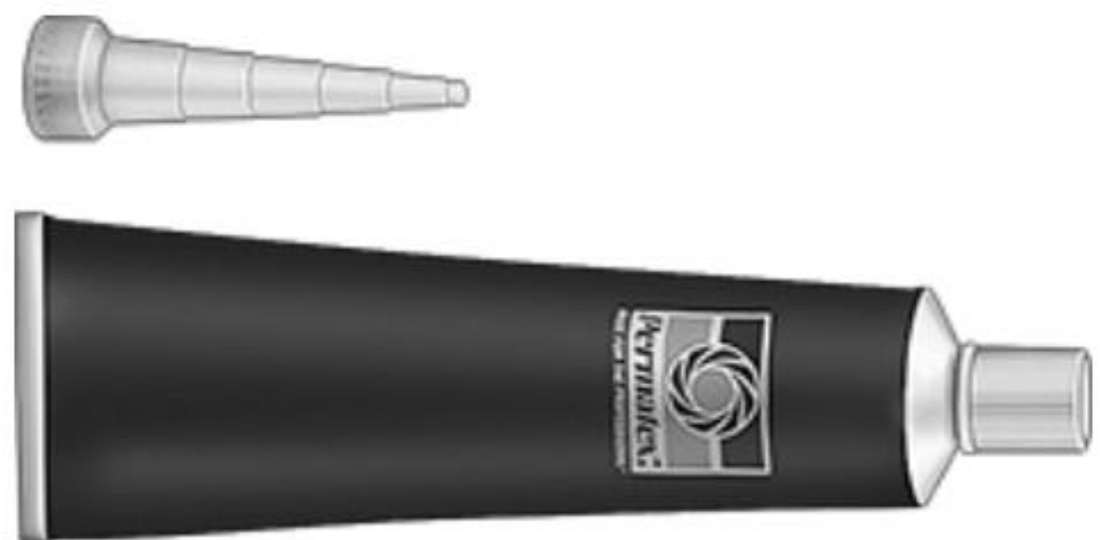

Figure 23 Gasket Maker Sealant, Permatex 800022, 3 oz. Tub [18] 


\begin{tabular}{|l|l|l|l|}
\hline Manufacturer & Permatex & Temp. Range & $-65^{\circ}$ to 400 \\
\hline Model No & 80022 & Begins to harden & $60 \mathrm{~min}$ \\
\hline Color & Blue & Full strength in & $24 \mathrm{hrs}$ \\
\hline Clarity & Clear & Max. gap size filled & $0.25^{\prime}$ \\
\hline
\end{tabular}

Table 9 Gasket Maker Sealant Data[18]

\subsubsection{LUBRICANT OF STATOR \& SLIDER}

The synthetic smooth-running grease for effective wear and corrosion protection.

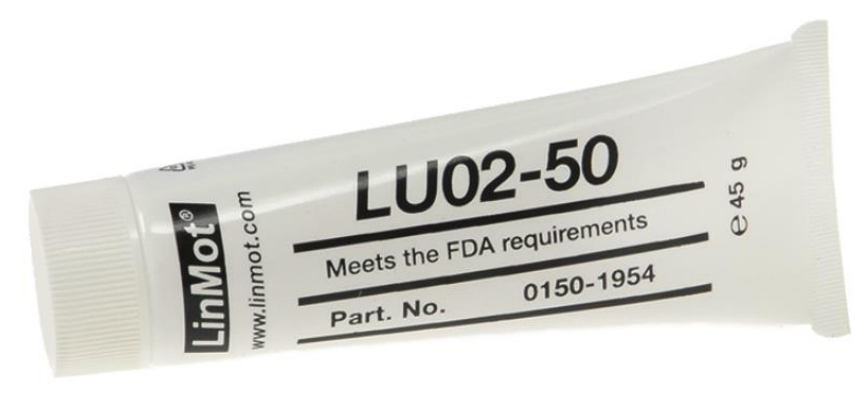

Figure 24 Lubricant LU02-50[19]

\subsection{VENDOR \& COST ANALYSIS}

The vendor analysis was crucial for this project as the components we were buying were for industrial use only and the cost varied across the suppliers. After rigorous communication, we shortlisted two top contenders to choose from; first was Westburne (Mississauga), an authorized dealer in Ontario, Canada for LinMot products. Second one was the MotionUSA, who were prompt in replies and provided good customer care but quoted significantly more compared to Westburne. As price was a key factor and Westburne offered a modest quote, we chose them for our academic project. Other fueling factors included the technical support offered by the Motion Specialist of Westburne, who addressed all our concerns regarding the products we ordered. After all of the required changes and updates, we placed an order with Westburne to LinMot on December $9^{\text {th }}$, 2019. Then we placed an order with McMaster-Carr (US) for washers, setscrews, nuts and a gasket. We shortlisted Structure Probe, Inc (US) as a vendor for TEM-grids and placed an order with them for tweezers. 


\section{CONCLUSION AND RECOMMENDATIONS}

The design of the thermophoretic sampling system is completed and we placed an order for the required components. Integrating all the components featured in Figure 25 will make the design ready.

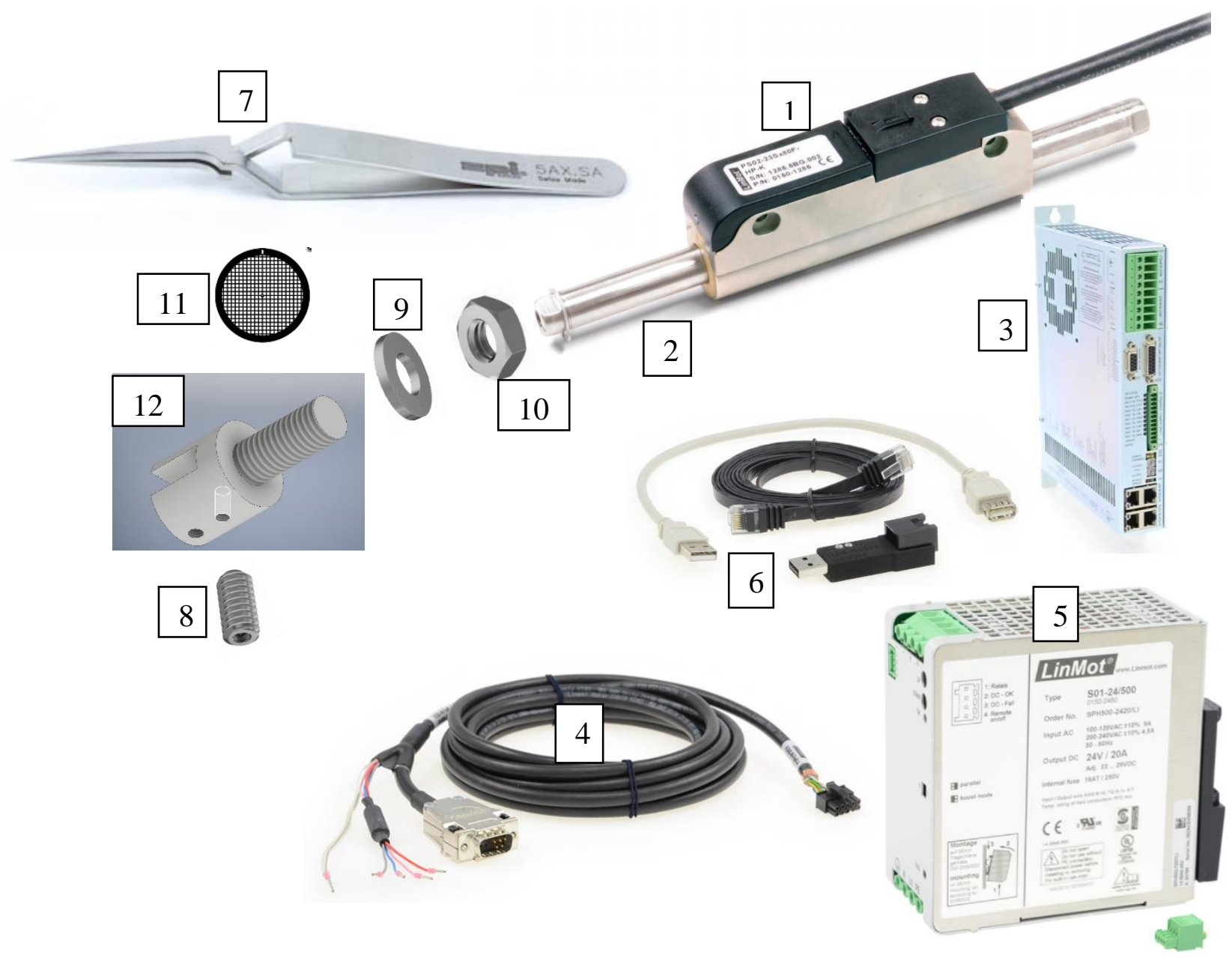

Figure 25 Thermophoretic sampling system all components

1. Linear motor(stator); 2. Slider; 3. Servo drive; 4. Trailing chain cable; 5. Power supply; 6. USB interface converter; 7. Tweezer, 8. Set screw; 9. Washers; 10.Thin hex nut; 11. Micro-grid; 12. Tweezer holder;

Using the instruction given in 2.4 .9 complete the assembly of the design with stator, slider and tweezer holder, it should resemble to Figure 26. Fully assembled thermophoretic sampling system (TSS) we designed should resemble to Figure 27 


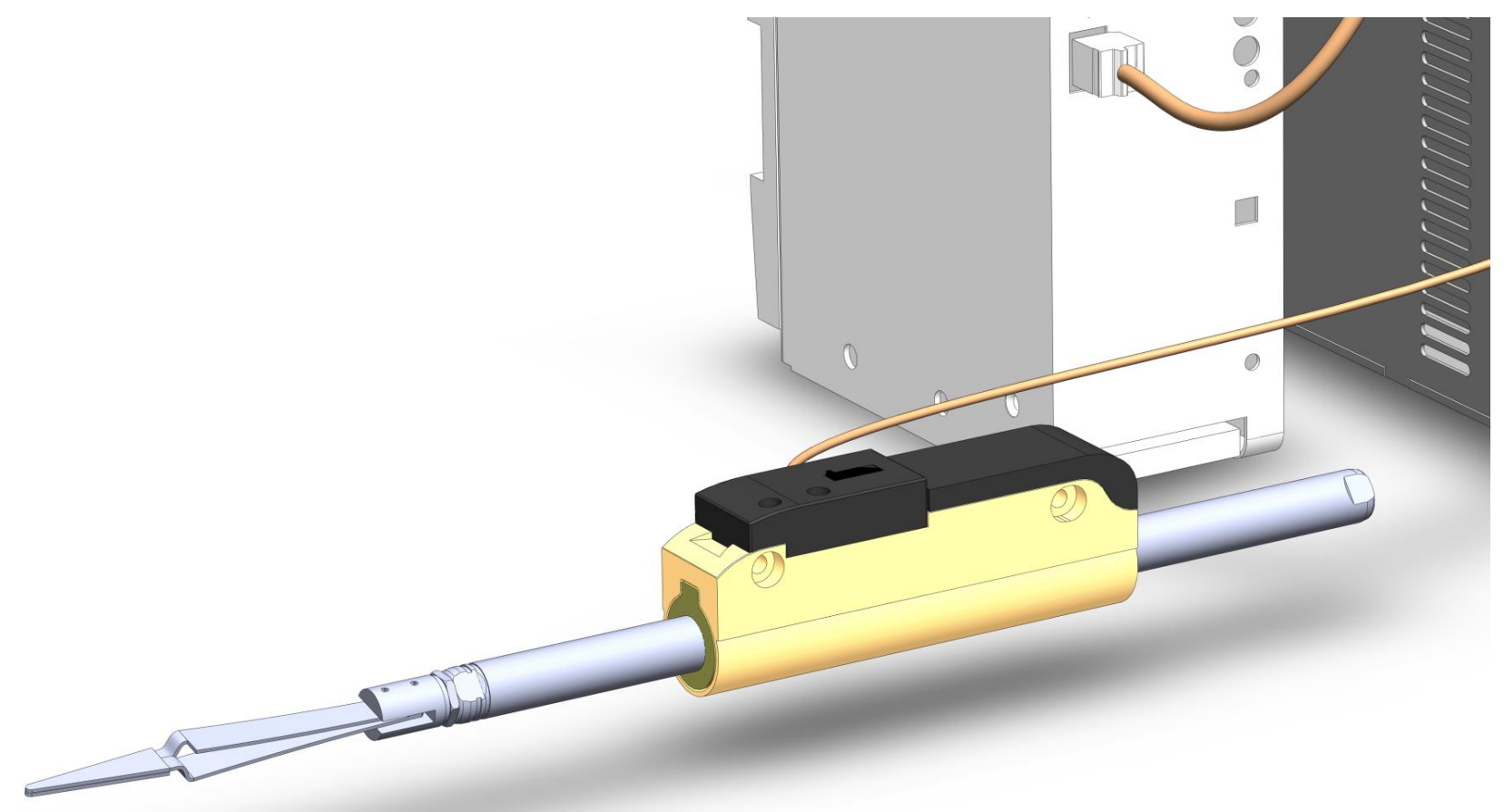

Figure 26 Assembled design of tweezer holder, slider and stator

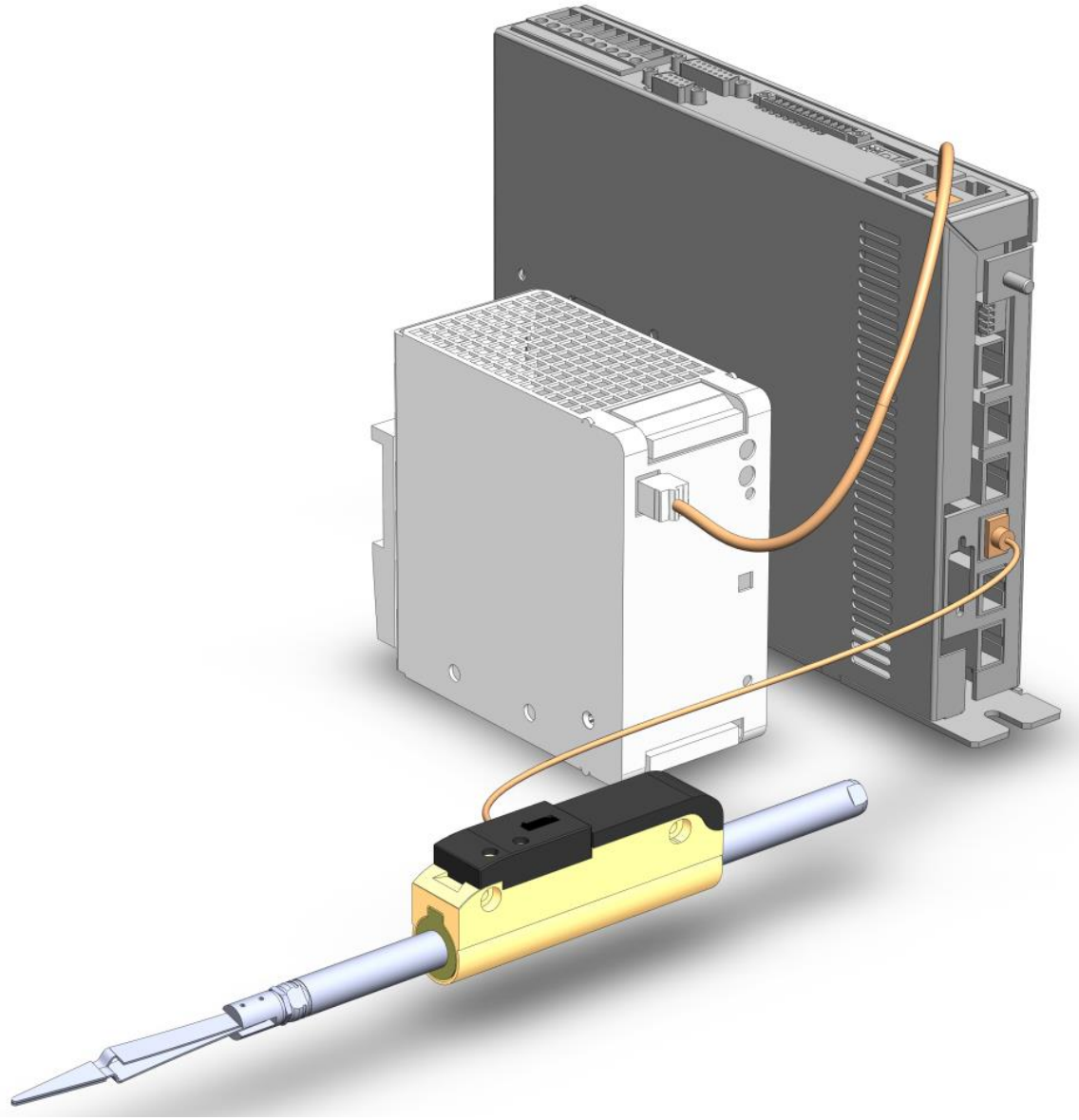

Figure 27 Fully assembled design of thermophoretic sampling system (TSS) 


\subsection{FUTURE SCOPE OF THE PROJECT}

The current scope of the project is only the design of the system. The further scope would be integrating the system and defining the sequence action that must be performed by the linear motor. All the required software and handbooks for the setup is provided on the LinMot website. All the links are placed in Table 1 in the respective row of the product for reference.

\subsection{RECOMMENDATIONS FOR SEQUENCING}

1. Stroke sequence is done in a three-phase motion. The first phase would be slowly reaching to the point just before the flames, namely the stroke point, then a fast stroke to the centre point of the flames with retractions as per the required residue time $(3 \mathrm{~ms}, 30 \mathrm{~ms}, 100 \mathrm{~ms})$ to the stroke point. Then the final phase is a slow retraction and a cool down to the initial point. Progressing in three phases would help in getting the required least residue time to $3 \mathrm{~ms}$, as the path that has to be travelled in ultra-high speed is reduced to just the radius of the burner.

2. The similar stroke is to be sequenced with an initial $90^{\circ}$ rotation and follow the same sequence as in point 1 .

Caution: As this linear motor is basically used for repetitive motions, the cool down sequence needs to be initiated and the end of the third phase so that the stroke won't be repeated. 


\section{APPENDIX}

Following was the in initial design iteration of the tweezer holder, but we did not go a head with this design as it is difficult to manufacture this by just using a lathe. This design led us to a final design that we came up with and discussed in the report. Final design in Figure 19 is easy to fabricate using just one piece of aluminum rod of dia. $10 \mathrm{~mm}$ as this is a design with two concentric shafts unlike the design in Figure 28.

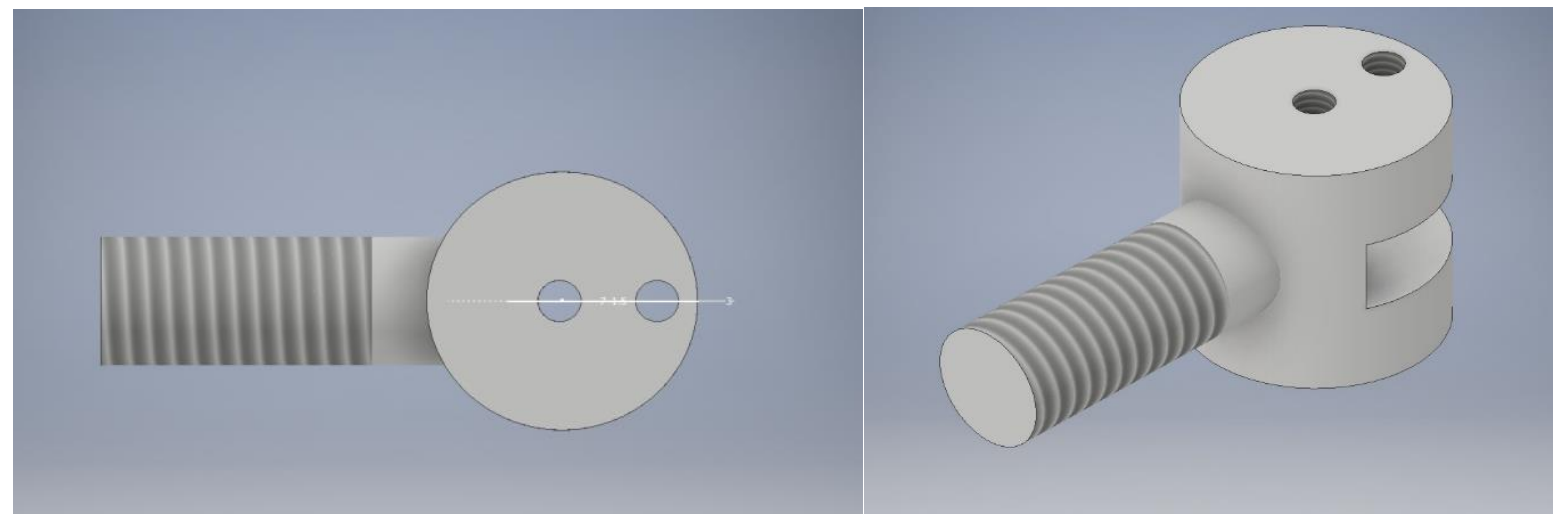

Figure 28 First design iteration of tweezer holder not easy to be fabricate

First design iteration of tweezer holder drawing and measurements, other noticeable change here is to use M1.6 for set screw, in the final design it is changed to M2.
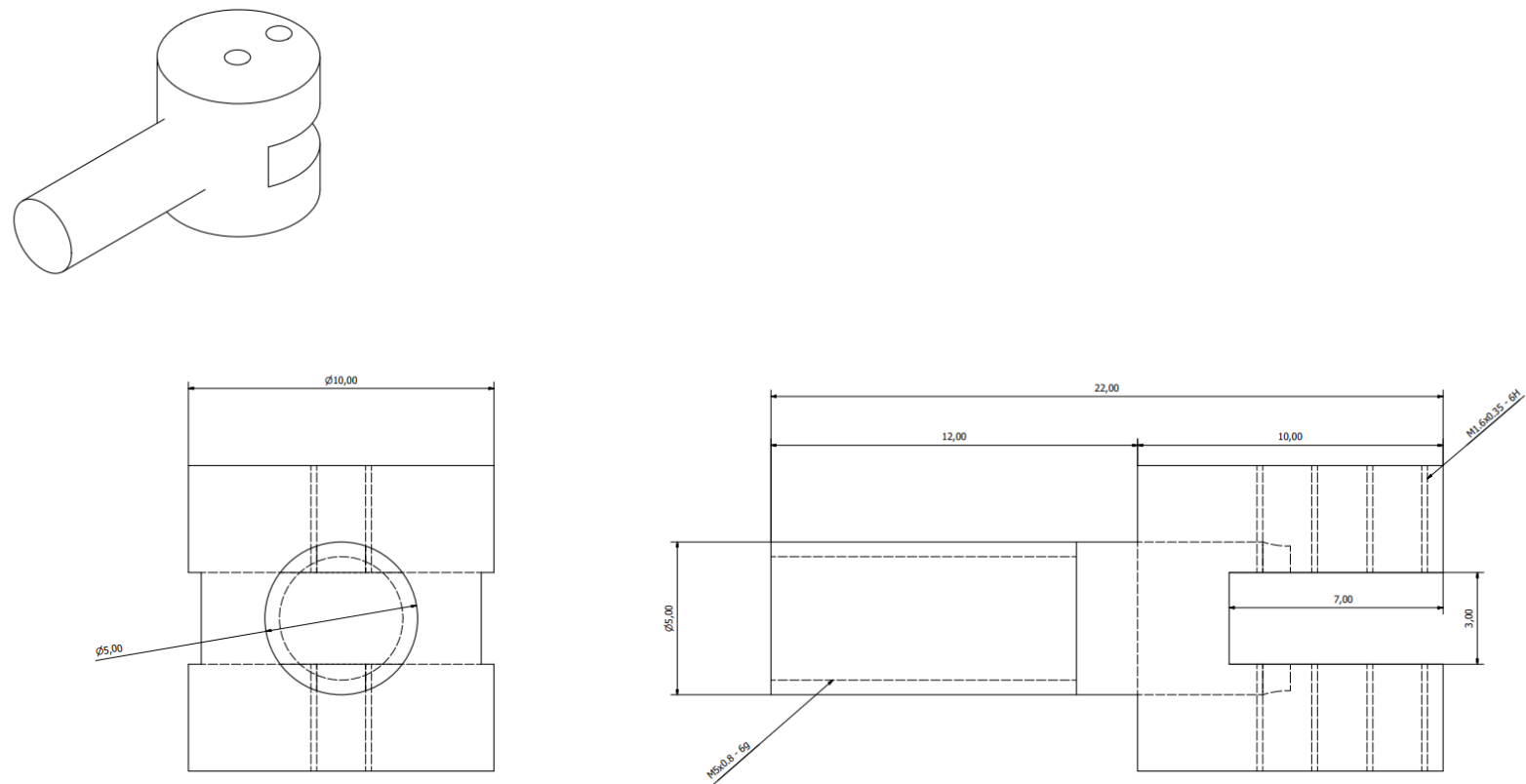

Figure 29 Drawing of first design iteration of a tweezer holder. 


\section{BIBLIOGRAPHY}

[1] H. Chu, W. Han, W. Cao, M. Gu, and G. Xu, "Effect of methane addition to ethylene on the morphology and size distribution of soot in a laminar co-flow diffusion flame," Energy, vol. 166, pp. 392-400, Jan. 2019, doi: 10.1016/j.energy.2018.10.093.

[2] M. Leschowski, T. Dreier, and C. Schulz, "An automated thermophoretic soot sampling device for laboratory-scale high-pressure flames," Review of Scientific Instruments, vol. 85, no. 4, Apr. 2014, doi: 10.1063/1.4868970.

[3] A. M. Vargas and Ö. L. Gülder, "A multi-probe thermophoretic soot sampling system for high-pressure diffusion flames," Review of Scientific Instruments, vol. 87, no. 5, May 2016, doi: 10.1063/1.4947509.

[4] M. Altenhoff, C. Teige, M. Storch, and S. Will, "Novel electric thermophoretic sampling device with highly repeatable characteristics," Review of Scientific Instruments, vol. 87, no. 12, Dec. 2016, doi: 10.1063/1.4971988.

[5] C. R. Shaddix and T. C. Williams, Soot: Giver and taker of light. American Scientist, 2007.

[6] Aristotle, The works of Aristotle. Penn State Electronic Classics Series Publication, 2005.

[7] Liner Motor (stator), “https://shop.linmot.com/E/product/0150-1285."

[8] Slider, "https://shop.linmot.com/E/product/0150-1519."

[9] Servo drive, "https://shop.linmot.com/E/product/0150-1771."

[10] USB converter, "https://shop.linmot.com/E/product/0150-2473.”

[11] Trailing chain cable, "https://shop.linmot.com/E/product/0150-2187."

[12] Power supply, "https://shop.linmot.com/E/product/0150-2480."

[13] Mesh, "https://www.2spi.com/item/3520c-mb/."

[14] Tweezers, "https://www.2spi.com/item/sn5ap-xd/."

[15] Set screw, "https://www.mcmaster.com/92605a043."

[16] Washer, "https://www.mcmaster.com/97725a510."

[17] Thin Hex Nut, "https://www.mcmaster.com/90710a037."

[18] Gasket Maker Sealant, "https://www.mcmaster.com/7535a12."

[19] Lubricant, "https://shop.linmot.com/E/product/0150-1954.” 